\title{
A COMPARISON OF CARBIDE AND OXIDE FUEL-COOLANT INTERACTIONS RESULTING FROM OVERPOWER TRANSIENTS
}

\author{
by \\ Lech Mync and Harold Trease \\ Reactor Analysis and Safety Division
}

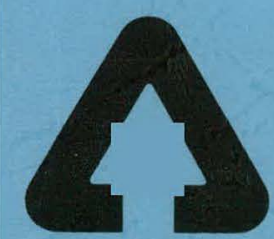

ARGONNE NATIONAL LABORATORY, ARGONNE, ILLINOIS

Prepared for the U. S. DEPARTMENT OF ENERGY

under Contract W-31-109-Eng-38 


\section{DISCLAIMER}

This report was prepared as an account of work sponsored by an agency of the United States Government. Neither the United States Government nor any agency Thereof, nor any of their employees, makes any warranty, express or implied, or assumes any legal liability or responsibility for the accuracy, completeness, or usefulness of any information, apparatus, product, or process disclosed, or represents that its use would not infringe privately owned rights. Reference herein to any specific commercial product, process, or service by trade name, trademark, manufacturer, or otherwise does not necessarily constitute or imply its endorsement, recommendation, or favoring by the United States Government or any agency thereof. The views and opinions of authors expressed herein do not necessarily state or reflect those of the United States Government or any agency thereof. 


\section{DISCLAIMER}

Portions of this document may be illegible in electronic image products. Images are produced from the best available original document. 
The facilities of Argonne National Laboratory are owned by the United States Government. Under the terms of a contract (W-31-109-Eng-38) between the U. S. Department of Energy, Argonne Universities Association and The University of Chicago, the University employs the staff and operates the Laboratory in accordance with policies and programs formulated, approved and reviewed by the Association.

\section{MEMBERS OF ARGONNE UNIVERSITIES ASSOCIATION}

The University of Arizona

Carnegie-Mellon University

Case Western Reserve University

The University of Chicago

University of Cincinnati

Illinois Institute of Technology

University of Illinois

Tndiana University

Iowa State University

The University of Iowa
Kansas State University The University of Kansas Loyola University Marquette University Michigan State University The University of Michigan University of Minnesota University of Missouri Northwestern University University of Notre Dame
The Ohio State University

Ohio University

The Pennsylvania State University

Purdue University

Saint Louis University

Southern Illinois University

The University of Texas at Austin

Washington University

Wayne State Universily

The University of Wisconsin

\section{NOTICE}

This report was prepared as an account of work sponsored by the United States Government. Neither the United States nor the United States Department of Energy, nor any of their employees, nor any of their contractors, subcontractors, or their employees, makes any warranty, express or implicd, or assumes any legal liability or responsibility for the accuracy, completeness or usefulness of any information, apparatus, product or process disclosed, or represents that its use would not infringe privately-owned righls. Ivfention of commercial products, their manufacturers, or their suppliers in this publication does not imply or connote approval or disapproval of the product by Argonne National Laboratory or the U. S. Department of Energy. 
Distribution Category:

LiIFBR Fuels and Materials Engineering and Development (UC-79b)

\section{A COMPARISON OF CARBIDE AND OXIDE \\ FUEL-COOLANT INTERACTIONS RESULTING FROM \\ OVERPOWER TRANSIENTS ${ }^{\dagger}$}

by

Lech Mync and Harold Trease ${ }^{\dagger \dagger}$

December 1977

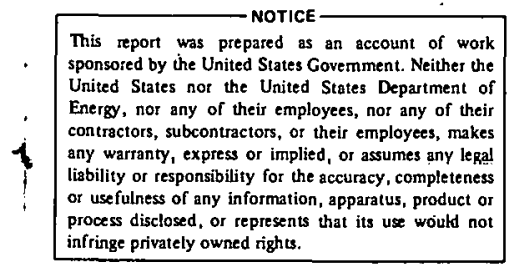

†ork performed under the auspices of the U.S. Department of Energy.

${ }^{+\dagger}$ Participant in Undergraduate Research Participation Program (Spring 1977), presently at University of Illinois, Urbana, Illinois. 
TABLE OF CONTENTS

Page

1. INTRODUCTION AND SUMMARY . . . . . . . . . . . . . . . . 1

2. SCOPE OF THIS STUDY ....................... 2

3. THE PLUTO MODEL (PLUTOI VERSION) . . . . . . . . . . . . . 3

4. TRANSIENT CALCULATIONS . . . . . . . . . . . . . . . 6

4.1 Case 1: Carbide Fue1-Coolant Interaction . . . . . . . 7

4.2 Case 2: Oxide Fue1-Coolant Interaction . . . . . . . . . 10

5. EXCHANGE OF INITIAL CONDITIONS, COOLANT CHANNEL GEOMETRIES AND FUEL PROPERTIES . . . . . . . . . . . . . . . . 14

5.1 Case 3: Ejection of Oxide Fuel into Carbide-Designed Environment . . . . . . . . . . . . . . . . . . 14

5.2 Case 4: Ejection of Carbide Fuel into Oxide-designed Environment . . . . . . . . . . . . . . . 15

6. CONCLUSIUNS AND SUGGES'ITONS FOR FURTHER CODE DEVELOPMENT • • • 17 REFERENCES . . . . . . . . . . . . . . . . . . . 20

LIST OF FIGURES . . . . . . . . . . . . . . . . . . . . . . i LIST OF TABLES . . . . . . . . . . . . . . . . . . . . . ii 


\section{LIST OF FIGURES}

No.

$\underline{\text { Page }}$

1 Fuel-Coolant Interaction Process . . . . . . . . . . 5

Pressure History at $\mathrm{R}_{\mathrm{o}}($ Case 1) . . . . . . . . 25

Extent and Shape of Carbide Distribution (Case 1) . . . 28

7 Reactivity History for Case 1............ . 29

8. Pressure History at $\mathrm{R}_{\mathrm{o}}$ for Case 2. . . . . . . . . 30

9. Extent of the Interaction Zone for Oxide . . . . . . . 31

10 Mass of Oxide Ejected (Case 2) . . . . . . . . . 32

11. Reactivity H1story for Case 2. . . . . . . . . 33

12 Extent of the Interaction Zone for Case 3 . . . . . . . 34

13 Mass of Ejected Oxide (Case 3). . . . . . . . 35

14 Comparison of Reactivity Effects in Case 1 and Case 3... 36

15 Development of the Interaction Zone in Case $4 \ldots . . . .37$

16 Mass of Ejected Carbide (Case 4) . . . . . . . . 38 


\section{LIST OF TABLES}

No.

$\underline{\text { Page }}$

1 Geometry, Fuel Properties, Initial and Boundary Conditions for the Carbide/Oxide Comparison . . . . . 21

2 : Transient Results for Cases 1 and 2 .......... 22

3 Comparison of Heat Transfer Effects . . . . . . . . 12 


\section{INTRODUCTION AND SUMMARY}

The consequences of carbide-fuel-coolant interactions (CFCI) resulting from overpower transients have been investigated with the PLUTO code ${ }^{l}$ (PLUTO1 version). The predictions are based on direct extrapolation from oxidedeveloped phenomenology. In addition the carbide results are compared to an "equivalent" oxide-fuel-coolant interaction (OFCI). The initial conditions for the fuel-coolant-interactions are based on predictions from whole core accident studies. ${ }^{2}$

The detailed calculations indicate that under these assumptions, using the oxide results as a standard of measure, the CFCI can be characterized by the following: (1) higher sodium temperatures and thus higher sodium vapor pressure in the interaction zone, (2) more rapid insertion of sodium voiding reactivity, (3) higher degree of z-symmetry (with respect to the rupture location) in the ejected fuel distribution, (4) more rapid growth of the interaction zore, and (5) an indication of the temporary shutting off of fuel ejection during the early stage of the interaction. It is concluded that the differences between CFCIs and OFCIs are attributed mainly to the differences. in fuel properties. Furthermore, it is shown that the differences in the boundary conditions, and the initial conditions do not contribute significantly to these results. 


\section{SCOPE OF THIS STUDY}

The objective of this study is two-fold: first, to uncover any unsuspected behavior (both numerical and physical) when analyzing carbide fuels, and second, to quantify the physically important parameters in comparing the carbide results to oxide results.

The first objective was achieved by a careful checkout of the PLUTOl code, which led to the following modifications to the code and observations about it:

1. All fuel propercy data are now supplied by the user as input; i.e., heat of fusion, mellimg lemperalure, diffuslvity of fuel, etc., have been moved from the source program to input data.

2. An adjustment to the void fraction calculation, so as to avoid negative heat transfer effects (heat transfer from coolant to fue1), has been made.

3. Additional information with regard to FCI energetics is printed out by the code.

4. $\Lambda$ numcrical coupling limitation between the pin-cavity nodal structure and the coolant channel nodal structure has been recognized, but can be coped with for the case of carbide fuel.

5. A plotting capability for the oxide/carbide comparison study has been developed.

'l'he second objective (the main objective) was completed by carrying out a series of parametric calculations. Only a limited number of cases are presented in this report. No attempt was made to define the best estimate; instead, the cases chosen seem to point out the essential differences between oxide and carbide fuel-coolant interactions initiated by a overpower transient. 


\section{THE PLUTO MODEL (PLUTO1 VERSION)}

As a part of continuing effort in examining the capabilities of existing accident analysis tools for advanced fuels, this report is restricted to the use of the PLUTO model. The use of PLUTO provides an additional estimate to previous predictions ${ }^{3}$ of CFCIs with the use of the SAS/FCI mode1.9 The major differences between the predictions obtained in this work and the previous work result from the different numerical modeling of FCIs and the fact that PLUTO1 is used as a stand-alone code. Unlike the use of PLUTO for this report, the SAS/FCI model was used in an integrated fashion. That is, with SAS/FCI the occurrences of FCIs have been coupled to a spectrum of phenomena other than FCIs in a whole core accident development. The coupling clouds the issue of carbide fuel interactions.

The details of the physics and the numerical treatment used by PLUTO are given in Ref. 1. For completeness, however, some of the fundamental assumptions are reiterated below:

1. The fuel/fission-gas mixture within the pin cavity is treated by a one-dimensional, homogenous compressible flow.

Comment: The presence of fission gas is a necessary condition for clad failure and ejection of fuel. This assumption restricts the mode1 to treat only. irradiated fuel. For carbide, other mechanišms, such as, transient fuel swelling, volumetric expansion of fuel as the fuel undergoes melting transition, and the fuel vapor pressure are possible alternative mechanisms for the ejection.

2. Continued fission heating of the fuel is ignored.

3. The ejected fuel is assumed to instantaneouely fragment (it is possible to have successive fragmentation within specified delay times) into spherical particles of a specified size. It is also possible to further fragment these particles into smaller ones after a certain delay time.

Comment: Because of the uncertainty in fragmentation mechanisms, the energy required for fragmentation is not taken into account. 
There are four theories which try to explain fragmentation: first, the hydrodynamic impact; ${ }^{4}$ second, the growth and collapse of vapor bubbles on the surface of the molten fuel; 5,6 third, fragmentation caused by thermal stresses; ${ }^{7}$ and fourth, the entrapment of coolant. 8 Under a variety of accident conditions, the four mechanisms may not be mutually exclusive, and they seem to depend on the material properties as well as on the hydrodynamics of the problem. For the present study, based on thermodynamic considerations, fragmentation can be viewed as a part of the natural process of establishing thermal equilibrium through an enhancement of heat transfer area.

4. 'lhe equation's of motion for the sodium- (Liquid and/or vapor) f1ssion-gas mixcure are those describing a compressible mixture. The mixture interacts thermally and mechanically with the incompressible fuel spheres.

Comment: a. The heat transfer (Q) from fuel to sodium is approximated by the usual heat transfer coefficient arguments: $Q \sim h\left(T_{f}\right.$ $\left.\mathrm{T}_{\mathrm{Na}}\right)(z, t)$. b. The heat ransfer coefflclent depends on the fuel properties and the coolant void fraction $(h \sim k / r(1-\alpha))(z, t))$, where $k=$ conductivity of fuel, $r=$ radius of fuel sphere and $\alpha=$ void fraction. c. The temperature of the ejected fission gas is assumed to be volume averaged between the fuel and sodium tempera-

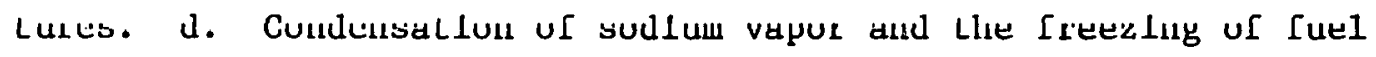
are included; however, no formation of sodium film on the clad, and no formation of solid fuel structures (fuel freezing on cold structures) is allowed. e. I'he mechanical interactions between a tuel particle and the surrounding mixture include the drag forces and frictional losses. f. A free surface boundary condition at the inlet and outlet of the coolant channel is assumed.

5. Coupling between the dynamics of the pin cavity, and the coolant channel determines the ejection of fuel based on pressure differences.

Briefly, the mathetical model consists of the fundamental conservation laws (mass, momentum, energy) expressed in the form of compressible fluid mechanics, which together with the equation of state, the thermo-mechanical coupling 
between components and the boundary conditions complete the specification of the problem. Figuratively, the main features of the model can be illustrated as shown in Fig. 1 below:

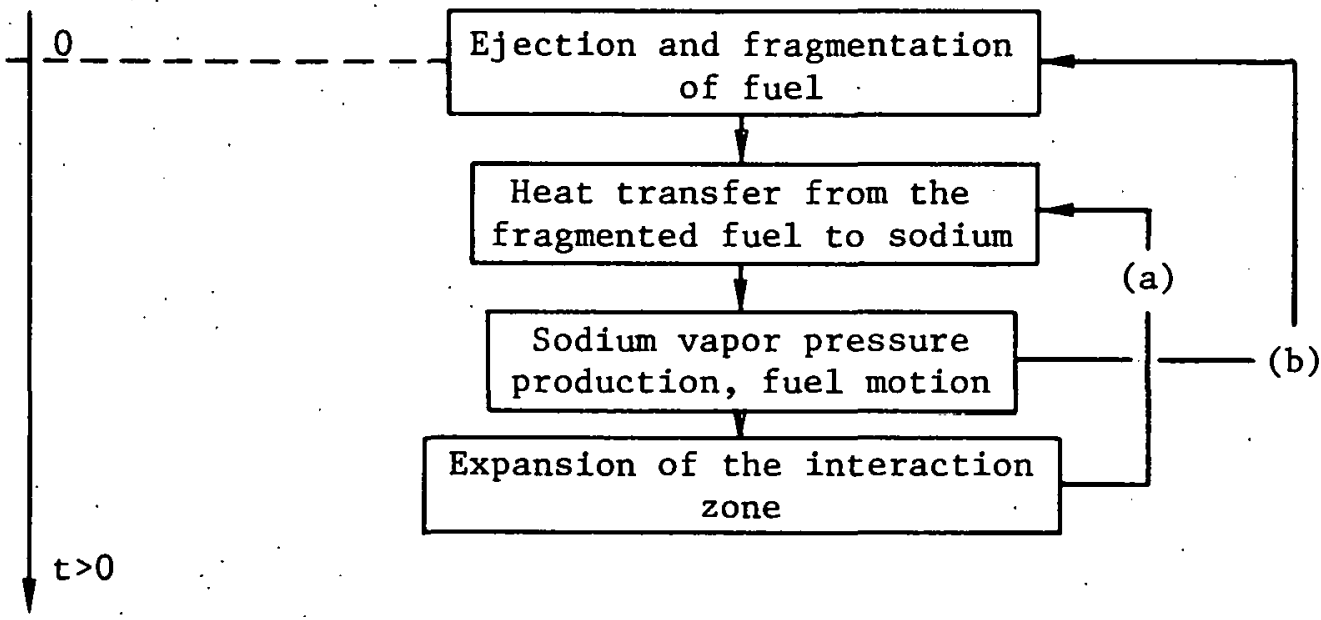

Fig. 1. Fuel-Coolant Interaction Process

The two lines (a) and (b) indicate that the development of the FCI depends on the past history, as well as on the initial conditions. They represent two feedback effects: (a) the expansion of the interaction zone has a negative effect on the heat transfer mechanism, and (b) the sodium vapor pressure production impedes the ejection of fuel. The feedback mechanisms make the model highly nonlinear. It is because of the nonlinearities that the extrapolation to other systems (different fuels) is nonlinear and difficult. The initial conditions, the boundary conditions, the fuel property data, and the subsequent hydrodynamic feedback are important in the development of FCIs and their implications on reactivity effects. 


\section{TRANSIENT CALCULATIONS}

- Representative coolant channels containing carbide and oxide pins were chosen from available $3000 \mathrm{MW}(\mathrm{th})$ core designs. ${ }^{3}$ The initial conditions for the PLUTO calculation resulted from a SAS $3 A$ calculation of a $0.5 \$ / \mathrm{sec}$ TOP event in each core. ${ }^{2}$ Table 1 lists the geometry, the initial temperatures at the time of fuel ejection. The details of the selected failure criteria are discussed in Reference.3. For the purpose of comparison, the location of the clad failure, the internal pin cavity pressure, and the fuel fragment size are assumed to be identical.

Four cases are described in the remainder of this report. The first two cases correspond to carbide-fuel interaction and oxide fuel-coolant interaction. The last two cases, respectively, correspond to the ejection of carbide fuel into a channel which is identical to that used in the oxide FCI calculation, and the ejection of oxide fuel into the channel used in the initial carbide FCI calculation. To illustrate the details of the analysis, a detailed discussion is presented only for the first case; the subsequent cases are discussed with less detail. The following definitions, and notations are introduced for cullvénillile:

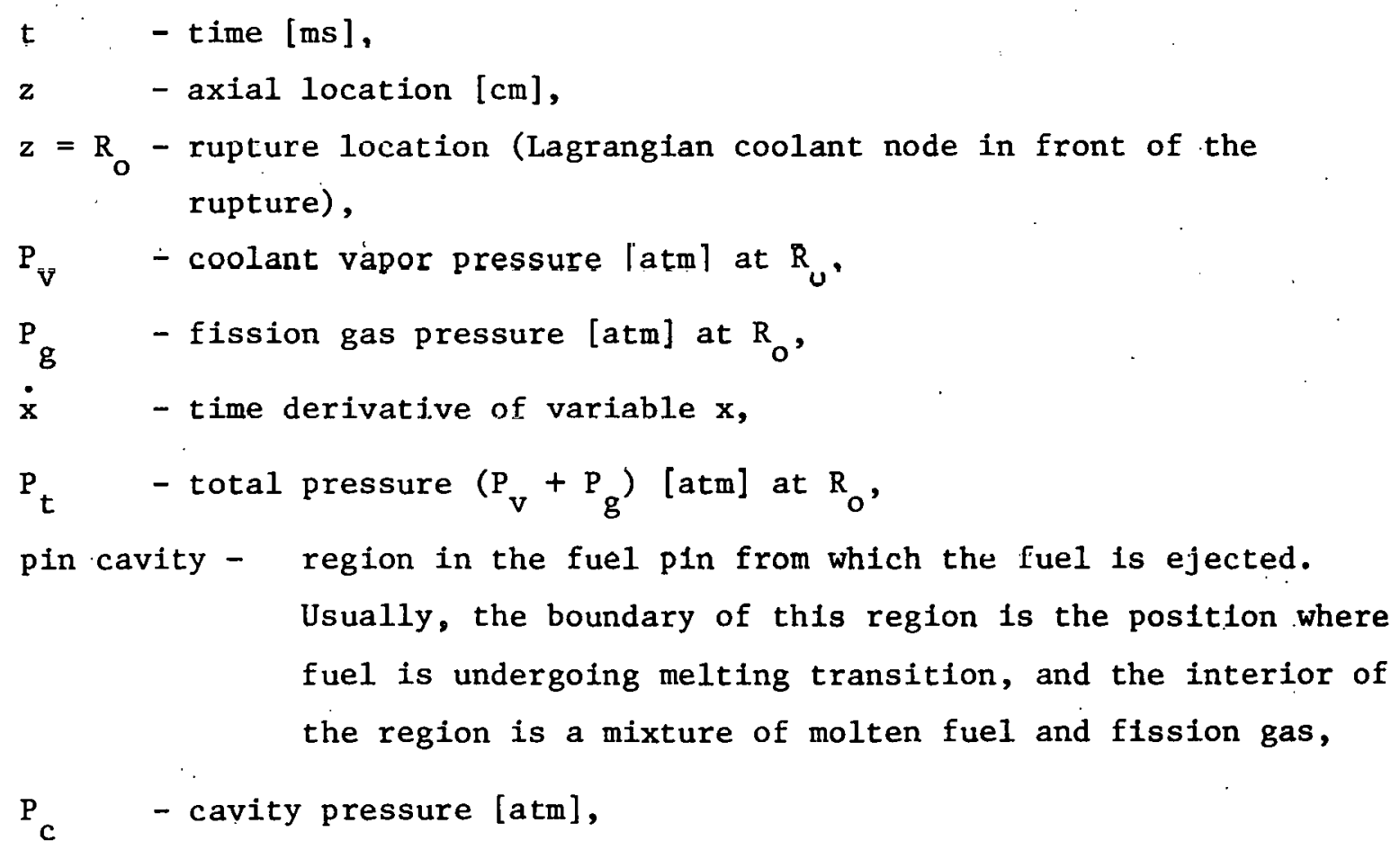




\begin{abstract}
interaction zone - region in the coolant channel, previously occupied by liquid $\mathrm{Na}$, with nonzero fuel mass after ejection,

$\mathrm{L}^{+}(\mathrm{z}, \mathrm{t}), \mathrm{L}^{-}(\mathrm{z}, \mathrm{t})$ - upper and lower boundaries of the interaction zone.
\end{abstract}

\title{
4.1 Case 1: Carbide Fuel-Coolant Interaction
}

For the purpose of orientation, the initial condition for this case resulted from $0.5 \$ / \mathrm{sec}$. reactivity insertion into an intact carbide-fueled LMFBR operating at full nominal power. ${ }^{3}$ Prior to the postulated clad failure (based on fuel melt fraction of 0.5 ) the sequence of events was rather simple: the increase in power level resulted in an increase of fuel and coolant temperatures followed by sodium-bond vaporization and fuel melting. The loss of bond event (by sodium vaporization) and subsequent gap closure (by initiation of fuel melting) determine the axial melt profile of fuel. This profile defines the boundary of the pin cavity from which the fuel is ejected. Coolant voiding was not predicted prior to satisfying the assumed clad failure criterion. Although the fuel melt fraction distribution was predicted to have a maximum above the core midplane, for the present study, clad failure was assumed to occur at the core midplane. An initial pin cavity pressure, $\mathrm{P}_{c}$ of $300 \mathrm{~atm}$ was achieved by allowing $4.2 \times 10^{-4} \mathrm{gm}$ of fission gas/gm of fuel to exist prior to the failure. Figure 2 illustrates the axial geometry for the carbide pin. The length of the rupture is $7.26 \mathrm{~cm}$, which in turn is dictated by the choice of the length of Lagrangian cells in the coolant channel.

Instantaneously at failure $0.33 \mathrm{gm}$ of fuel and $0.00014 \mathrm{gm}$ of fission gas is ejected into the Lagrangian node in front of the rupture, resulting in a fission gas pressure pulse of $180 \mathrm{~atm}$. The ejected fuel is assumed to be fragmented instantaneously into spheres of radius $=0.25 \mathrm{~mm}$. Figure 3 illustrates the total pressure $P_{t}=P_{v}+P_{g}$ as a function of time at the. rupture location $\left(Z=R_{o}\right)$, where $P_{v}=$ coolant vapor pressure and $P_{g}=$ fission gas pressure. For $0<t<3.2$ msec, $\dot{\mathrm{P}}_{\mathrm{v}}>0, \dot{\mathrm{P}}_{\mathrm{g}}>0$ and $\dot{\mathrm{P}}_{\mathrm{t}}<0$; i.e., the total pressure history in front of the rupture is dominated by fission gas pressure. At $t=3.2 \mathrm{msec}$, the fission gas and sodium vapor pressures become equal as fuel-to-coolant heat transfer begins to dominate the total pressure history. The fuel particles begin to freeze (melt fraction $\sim 0.9$ ) while the void fraction increases. At $t=3.3, \dot{\mathrm{P}}_{t}$ at $\mathrm{R}_{\mathrm{o}}$ changes sign as the sodium vapor pressure dominates. 
Figure 4 illustrates the mass of fuel ejected from the cavity as a function of time. For $4.0<t<8.8, \mathrm{P}_{t}$ exceeds the cavity pressure, $\mathrm{P}_{c}$, causing a temporary termination of ejection. During this period, the increasing void fraction results in a slower rise of coolant temperature.

The second maximum of $\mathrm{P}_{t}$ occurs at $\sim 6 \mathrm{~ms}$, where the reduced heat transfer and the inertial constraint by the liquid slug begins to decrease the pressure at $\mathrm{R}_{\mathrm{O}}$. Figure 5 shows that the maximum sodium temperature reached the value of $1930^{\circ} \mathrm{K}$, which corresponds to the second pressure peak of 65 atm shown in Fig. 3. Table 2 indicates that, at $R_{0}$, the void fraction is rapidly increasing, while the fuel is at melting temperature with melt fraction < 1 .

At $t=8.8 \mathrm{~ms}$, fuel ejection resumes as $\mathrm{P}_{c}>\mathrm{P}_{t} \cdot$. The high void fraction $(0.75)$ at $R_{0}$ reduces the heat transfer rate, and the continued growth of the interaction zone is mainly by the expansion work of sodium vapor against the constraining liquid slugs. Until the time $t \sim 15 \mathrm{~ms}$, Figs. 3 and 5 show that at $\mathrm{R}_{\mathrm{o}}$, the sodium pressure and temperature decreases rapidly. However, the pressure decreases at a slower rate than the initial fission gas pressure. For $t \lesssim 15 \mathrm{~ms}$, the fuel-to-coolant heat transfer maintains a slower rate of sodium vapor pressure, and finally, when the temperature reaches the constant clad temperature $\left(1150^{\circ} \mathrm{K}\right)$. The sodium temperature is assumed to remain at that value, resulting at a constant pressure of $\backsim 1$ atm.

The discussion to this point has concentrated on the Lagrangian node at the rupture location $R_{0}$. As a result of the instantaneous ejection-fragmentation assumption, the fuel particles experience the following forces: 1) gravity, 2) pressure gradient, 3) drag with the surrounding fluid, and 4) friction with the coolant channel walls. Introduction of a fuel particle(s) by the above forces) into an adjacent Lagrangian node results in a similar but milder thermal interaction when compared to the inceraction at $R_{0}$. The Interactiun is weaker because the fuel exchanged heat to sodium prior to leaving $R_{0}$. The nodes adjacent to the node at $R_{0}$ are coupled hydrodynamically (by the usual continuity requirements) and result in a growth of the interaction zone as indicated in Fig. 6. Initially, the particle migration time constants are longer than the time constants associated with fuel ejection; the fuel distribution therefore remains peaked in the vicinity of $R_{0}$. As the rate of fuel 
ejection decays (Fig. 3), the fuel distribution tends to shift upward and at the same time, produces two peaks oriented symmetrically about the peak at $R_{0}$. This phenomenon is due to the pressure gradient and drag forces on the earlier ejected particles. The competing effects of slip between sodium-vapor/fission gas and particles, and sodium vapor pressure gradients result in somewhat complex fuel distribution as a function of time. For times $>30 \mathrm{~ms}$, the fuel distribution can be best characterized as having more fuel smeared above $R_{0}$ than below $R_{0}$. The skewness (1lustrated in Fig. 6) can be explained by the fact that the upward direction is the preferred direction of motion; pressure at the top is lower than the pressure at the bottom of the coolant channel. The initial flow reversal occurred at the inlet, at $t=2 \mathrm{~ms}$. At $t=68 \mathrm{~ms}$, the lower interface of the bottom sodium slug resumes an upward motion, while the upper liquid slug decelerates as the interaction zone pressure decreases.

The quenching of the thermal interaction by higher void fraction, lower fuel ejection rate, and the expansion of the sodium vapor results in an upward translation, rather than a continued growth of the interaction zone. The maximum $\left(\mathrm{L}^{+}(z, t)-\mathrm{L}^{-}(z, t)\right.$ occurs at $t=90 \mathrm{~ms}$ (prior to the termination of the calculation), while both $\mathrm{L}^{+}$and $\mathrm{L}^{-}$are moving upward.

Fuel reactivity effects are based on tracking the fuel motion in the interaction zone, as well as the pin cavity. The coolant reactivity is based on the void fraction distribution throughout the channel. Fuel and coolant reactivity worth curves whose shapes resemble those used in Ref. 3 have been used in this study. The worths are peaked at the core midplane, and approach zero at the axial edge of the core. Since the worth curves serve only a bookkeeping purpose (i.e., reactivity has no feedback effect on the FCI within the PLUTO content), the numerical magnitudes of the reactivity worths are therefore of no concern for this comparison study.

Figure 7 shows the fuel and coolant, and the sum of the two reactivities as a function of time. The sodium void reactivity increases until $t \sim 20 \mathrm{~ms}$; at this time the $\mathrm{L}^{+}$reaches the top of the active core region. During the time interval $20 \lesssim t \lesssim 32$ the void reactivity increases at a slower rate because of the downward motion of $\mathrm{L}^{-}$. For $t>32$, the void reactivity remains constant because the $\mathrm{L}^{+}$and $\mathrm{L}^{-}$are above and below the active core region, respectively. 
Therefore, within the actual core length, the reduced heat transfer appears to maintain a void fraction distrubtion with constant void fraction (integral of void fraction distribution).

The fuel reactivity, illustrated in Fig. 7, shows a monotonic and uniform decrease. To pick out the general features, the fuel motion can be broken up into three time periods; first, the period furing which the $\mathrm{L}^{+}$and $\mathrm{L}^{-}$do not overlap the pin cavity length; the second, the period during which the fuel particle distribution remains in the active core region; and the third, the period during which the $\mathrm{L}^{+}$and $\mathrm{L}^{-}$are beyond the active core length boundaries. In the first period, the peak concentration of fuel remains at $\mathrm{R}_{\mathrm{o}}$; the $\mathrm{L}^{-}$and $\mathrm{L}^{+}$interfaces reach the lower and upper boundaries of the pin cavity at $t=7$ and $t=16 \mathrm{~ms}$, respectively. In other words, the pressure gradients resulc in predominantly upward fuel motion with a peak in the vicinty of $R_{0}$. The monotonically decreasing reactivity indicates that the time constants associated with the fuel redistribution in the pin cavity are longer when compared to the time constants corresponding to the motion of fuel particles in the coolant channel. In fact, the velocity of the fuel particles is $\sim 10$ times higher than the velocity of the fuel/fission gas froth in the pin. In the second period, the fuel distribution begins to form peaks above and below $R_{0}$. Because of the large void fraction, the drag term appears to be the dominant factor in the smearing of the fuel particle distribution. The $\mathrm{L}^{+}$and $\mathrm{L}^{-}$reach the top and bottom of the core region at $18 \mathrm{~ms}$ and $31 \mathrm{~ms}$, respectively. In the third period $(t>30)$, the fuel motion in the pin cavity has negligible reactivity effects. This is because the rate of fuel ejection is rapidly decreasing, and the monotonic decrease of reactivity is governed by relocation of fuel to the outside of the active core region. At the end of the calculation, the total reactivity has decreased by the relocation of fuel, while the sodium void reactivity is at its maximum.

\subsection{Case 2: Oxide Fue1-Coolant Interaction}

For oxide overpower transient, the prediction of clad rupture is determined more mechanistically. That is, the fallure is determined by exceeding the temperature-dependent tensile strength of the clad. Detailed discussion of other clad failure criteria are found in Reference 9. Because of the differences 
in clad failure criteria for oxide and carbide pins, the pin cavity in oxide pin is longer than in the carbide pin.

This case and case 1 are defined to be equivalent because of the following similarities:

1. The initiator in both cases was a $0.5 \$ / \mathrm{sec}$ transient overpower event calculated with SAS3A.

2. Both cases resulted from a whole core accident involvement. The reactor environment in which both FCIs were predicted to occur correspond to the same nominal power level (3000 $\mathrm{MW}(\mathrm{th})$ ) of the reactor.

3. The selected.coolant channels did not experience any coolant boiling prior to satisfying the FCI criteria. Table 1 lists other differences and similarities in the initial temperatures, geometries and the fuel properties used in case 1 and this case.

Providing the FCI-phenomenology holds for both fuels, and in view of the similar situations under which FCIs were predicted to occur, the two cases provide, in a limited sense, a useful comparison under equivalent accident conditions.

Immediately following clad rupture, the mixture of molten oxide $\left(\mathrm{T}=3290^{\circ} \mathrm{K}\right)$. and fission gas is ejected by an assumed pin cavity pressure $\left(\mathrm{P}_{\mathrm{c}}=300\right.$ atm). The particle size, the location, and the length of the rupture are assumed to be the same as in case 1. The ratio of the (mass of fuel/mass of coolant) at $R_{0}$ is the same for both cases. This ratio may be due to the numerical treatment of the ejection process. The initial pressure pulse at $R_{0}$ is mainly. due to the initially ejected fission gas.

Figure 8 illustrates the pressure history at $R_{0}$. Due to the reduced heat transfer (lower conductivity of oxide), the pressure decays more rapidly than in the carbide case. In the carbide case, the sodium vapor pressure significantly dominates the fission gas pressure, at least for a short period of time $(4<t<14)$, during the initial stage of CFCI transient. For oxide, however, there was no time during the transient where the sodium vapor pressure dominated 
the fission gas pressure at $R_{0}$. This difference can be attributed to two items: 1) the differences between the oxide and carbide fuel conductivity, resulting in lower heat transfer rates in the case of oxide, and 2) the lower inertial confinement in the oxide channel. The effectiveness in the conductive heat transfer can be best illustrated by examining the temperatures of sodium and fuels tabulated below in Table 3.

\section{Table 3. Comparison of Heat Transfer Effects}

Carbide (Case 1) Oxide (this Case)

$\begin{array}{rrrr}\mathrm{T}_{\mathrm{Na}}\left(\mathrm{t}_{\mathbf{s}}\right)-\mathrm{T}_{\mathrm{Na}}(0) & {\left[{ }^{\circ} \mathrm{K}\right]} & 930 & 380 \\ \mathrm{~T}_{\mathrm{f}}\left(\mathrm{t}_{\mathrm{f}}\right)-\mathrm{T}_{\mathrm{f}}(0) & {\left[{ }^{\circ} \mathrm{K}\right]} & -320 & -60 \\ \mathrm{t}_{\mathrm{S}} & {[\mathrm{ms}]} & 6 & 8 \\ { }^{\mathrm{t}_{\mathrm{f}}} & {[\mathrm{ms}]} & 2 & 4\end{array}$

In Table 3, $\mathrm{T}_{\mathrm{Na}}=$ sodium temperature, $\mathrm{T}_{\mathrm{f}}=$ fuel temperature, $\mathrm{t}_{\mathrm{s}}=$ time at which the first maximum of sodium temperature occurred at $R_{n}, t_{f}=$ time at which the first minimum of fuel temperature occurred at $R_{0}$. It can be seen from Table 3 that the relative rates of increase of sodium temperatures, and the decrease of tuel temperatures are, respectively, $\sim 3.3$ times and $\sim 10$ times more rapid in the carbide system. Such differences in $\mathrm{T}_{\mathrm{Na}}$ and $\mathrm{T}_{f}$ are expected because of the higher diffusivity of carbide and stronger hydrodynamic feedback (higher void fraction) in CFCI.

The extent of the interaction zone for this case is shown in Fig. 9. The lower interaction zone pressure and the lower inertial constraint implies lower pressure gradients and a narrower distribution of oxide fuel particles. The most significant difference between case 1 and this case is the early simultaneous upward translation and expansion of the oxide interaction region.

Figures 10 and 4 illustrate the comparison of the ejected masses of fuels as a function of time. No indication or temporary termination of oxide fuel ejection is observed. Despite the fact that the ratio of initially ejected masses of 
fuels is 22 , and the volume ratio of available coolant for immediate contact is also 22 ; near the end of the calculation, the respective ratios reach the asymptotic value of $\sim 1$ and 24.6 . The 4.6 corresponds actually to the volume ratio of coolant channels (not including the pin) into which the fueis are distributed. The fact that the ejected fuel mass ratio did not remain at 2 , indicates the CFCI presents a greater impedance to fuel ejection. Furthermore, the same asymptotic mass of carbide fuel ejected results in an interaction zone $\sim 2.3$ times larger than in the case of oxide.

Figure 11 illustrates the reactivity effects in this case. Because of the different masses of fuel and coolant involved in the CFCI and OFCI, the magnitude of the reactivities are of little interest (the same worth curves were used for case 1 and this case). The fact that the maximum of the void reactivity in the CFCI is 3.3 times higher, gives an idea of the relative amount of sodium mass removed from the core region.

In both cases, the fuel reactivity decreases at roughly the same rate, and reaches the same final value. The fuel reactivity worths are symmetric with a maximum at $R_{0}$. The fragmented carbide distributes itself more symmetrically about $R_{0}$. In the case of oxide, the symmetry breaks down, and most of the ejected fuel is above $R_{o}$ in a volume $\sim 2.3$ times smaller than in the case of carbide. 


\section{EXCHANGE OF INITIAL CONDITIONS, COOLANT CHANNEL GEOMETRIES AND FUEL PROPERTIES}

As indicated in sections 3 and 4 , the fuel properties alone may not be the key reason that differences are observed between carbide- and oxide-induced fuelcoolant interactions. Other differences are less obvious. For example, the temperature of ejected oxide is higher, yet the interaction is weaker. The mass of sodium in the carbide channel is $\sim$ twice that of the oxide channel this probably delays the pressure decrease in the carbide interaction zone and causes the termination of carbide ejection. These concerns suggest the following proposition: suppose that oxide fuel is ejected into carbide designed environment and vice versa. Although these cases are physically unrealistic, the flexibility of PLUTO permits such simulations to be made. The resulting cases provide a more penetrating insight into the oxide/carbide comparison analysis. Two cases, presented below, examine the results of the calculations.

\subsection{Case 3: Ejection of Oxide Fuel into Carbide-Designed Environment}

In this case, the thermophysical properties and the initial temperatures corresponding to those of oxide fuel (case 2) are used in carbide-designed geometry. Due to the differences in initial tuel temperatures, the fission-gas content was slightly altered to provide the 300 atm of pin cavity pressure. The velocity and temperature of coolant correspond to those used in case 2 .

Figure 12 illustrates the extent of the interaction zone, which by comparison to Figures 6 and 9, resembles the evolution of oxide-induced FCI (case 2). Because of the higher inertial constratint by the lower and uppper liquid (compressible) slugs, the $L^{-}$interface returns to $R_{0} \sim 10 \mathrm{~ms}$ earlier than in case 2 , while the $\mathrm{L}^{+}$interface begins to decelerate sooner.

Figure 13 illustrates the mass of oxide ejected as a function of time. In comparison to case 1 (ejection of carbide), no temporary termination of oxide ejection occurs in case 3; however, the mass of fuels ejected into both cases reaches the same asymptotic value. This observation indicates that the differences in fuel properties, rather than the differences in coolant channel constraint, result in the termination of fuel ejection. 
Due to the fact that the same masses of fuel are ejected into identical coolant channels, one may examine the relative reactivity effects and deduce the importance of carbide- and oxide-induced FCIs. Figure 14 illustrates this comparison. The oxide-induced fuel reactivity exhibits a higher degree of hydraulic-sweepout-fuel relocation in the direction of initial coolant flow. Because of the higher pressures, $\mathrm{P}_{\mathrm{v}}$, in the carbide-induced $\mathrm{FCI}$, the fuel relocation is more symmetric about $R_{0}$, resulting in a less negative fuel reactivity.

The most striking difference in cases 1 and 3 is in the maximum reactivities and their time derivatives. The relative ratio of the maximum sodium void . reactivities (carbide-induced void reactivity/oxide-induced void reactivity) is $\mathbf{1 . 6}$. This ratio indicates that in the core region, 1.6 times more sodium is vaporized in carbide-induced FCI than in oxide-induced FCI. The maxima of the carbide- and oxide-induced void reactivities occur at $t \sim 25 \mathrm{~ms}$ and $\mathrm{t} \sim 50$ $\mathrm{ms}$, respectively, indicating that the ratio of the void induced ramp-rates (carbide/ oxide) is $\sim 3.2$.

\subsection{Case 4: Ejection of Carbide Fue1 into Oxide-designated Environment}

Assumptions reverse to those in case 3 are taken. That is, carbide fuel with an initial temperature corresponding to the temperature used in case 1 was ejected into a coolant channel of case 2 .

The initial mass of carbide injected in this case is $0.16 \mathrm{gm}$, and with continued ejection, the mass reaches an asymptotic value of $65 \mathrm{gm}$. The extent of the ejected carbide distribution as a function of time is shown in Fig. 15. By comparison to previous cases, the maximum extent. $E_{4}=\max \left(L^{+}-L^{-}\right){ }_{4}$, of the ejected fuel takes on an intermediate value. In fact, $E_{3}<E_{2}<E_{4}<E_{1}$, where the subscripts $1,2,3,4$ correspond to cases $1-4$. Ihis result is rather surprising, since the inertial constraint by the compressible liquid slugs in cases 2 and 3 is lower than in this case; and furthermore it would appear that $\mathrm{E}_{1}<\mathrm{E}_{4^{\circ}}$. The paradox can be explained as follows: In the initial stages ( $t$ $\lesssim 20 \mathrm{~ms}, \mathrm{E}_{1}<\mathrm{E}_{4}$ ), the growth of the interaction zone in case 4 is actually slightly faster than in case 1 , thus indicating that the larger mass of sodium in the carbide system plays a role. For $t>20 \mathrm{~ms}$, however, the smaller 
amount of carbide ejected and the larger heat capacity of sodium (there is more mass of liquid sodium per given mass of fuel) result in the interaction zone beginning to quench more rapidly in case 4. At later times (t $\gtrsim: 60 \mathrm{~ms})$, case 4 exhibtis oxide-1ike FCI development as the interaction zone begins to be translated upward.

Figure 16 shows the mass of carbide ejected as a function of time. No temporary termination of fuel ejection is predicted; however, there is a rapid decrease in the ejection rate for $6 \mathrm{~ms}<\mathrm{t}<10 \mathrm{~ms}$. The reactivity effects are of intermediate value between cases 1 and 2 . 


\section{CONCLUSIONS AND SUGGESTIONS FOR FURTHER CODE DEVELOPMENT}

Because of the heat-transfer-hydrodynamic coupling, the comparison between oxide and carbide fuel-coolant interactions involves an examination of highly non-linear systems. Not all FCI aspects that are of interest can be linearly extrapolated. To summarize, Table 4 lists an over-view of the more important results. Since the oxide results (case 2) are more believable, and in some cases, verifiable by experiment 10,11 the results of cases 1,3 , and 4 are conveniently normalized with respect to case 2 . The entries in the table are in multiples of case 2. The horizontal entries need some explanation:

$\underline{\text { Line } 1}$ - an average rise in sodium temperature $=\dot{\mathrm{T}}_{\mathrm{Na}}=\left(\mathrm{T}_{\mathrm{Na}}\left(\mathrm{t}_{\mathrm{T}}\right)-\mathrm{T}_{\mathrm{Na}}(0)\right) /$ $t_{T}$, where $t_{T}$ is the time at which the maximum $T_{N a}$ has occurred;

Line 2 - maximum sodium vapor pressure at $R_{0} \cdot$ (It is interesting to note that in all cases the transient-maximum of the pressure $P_{t}$ is at $t$ $=0^{+}$, due to the ejected fission gas, rather than due to the FCI.);

Line 3 - maximum size of the interaction zone $-\max \left(L^{+}(z, t)-L^{-}(z, t)\right.$;

Line 5 - average rate of sodium void reactivity =

$\frac{\rho_{\mathrm{Na}}(t \rho)-\rho_{\mathrm{Na}}(0)}{t_{\rho}}$, where $t_{\rho}$ is the time at which the maximum $\rho_{\mathrm{Na}}$ (1ine 4) occurs;

Line 9 - asymmetry of the interaction zone =

$$
\frac{L^{+}(z, t)-R_{0}}{\left|L^{-}(z, t)-R_{0}\right|}
$$


Table 4 indicates that with the exception of sodium vapor pressure, all listed results differ by less than an order of magnitude. The sodium vapor pressure appears to distinguish the carbide from the oxide FCIs. This observation can be deductively attributed to the following items:

(i) The initial and boundary conditions for cases 1-4 are within an order of magnitude.

(ii) Fuel property data, with the exception of thermal diffusivity, $(\mathrm{k} / \rho \mathrm{c})$ carbide/(k/oc) oxide $\sim 14$ differ by a factor of less than an order of magnitude.

(iii) The higher diffusivity of carbide implies that carbide responds faster to temperature variations on its surface.

(iv) Items (iii) and (i) imply higher sodium temperatures with carbide.

(v) The exponential (highly non-linear) dependence of sodlum vapor pressure on the temperature of sodium $P=\exp \left(\frac{a}{T}\right)$ can result in large pressure differences occurring because of small temperature differences (e.g., $10 \% \Delta \mathrm{T} \rightarrow$ $80 \% \Delta \mathrm{p}$. .).

In order to provide more certainty into these predictions, it is necessary to know the conditions under which carbide will fragment, the size of fragmented carbide, and the mechanism for ejection. In addition, code modifications are required to further address the following matters:

(i) A treatment of sodium-bonded carbide pins, where the ejection of sodium vapor prior to fuel ejection is possible, is required.

(ii) The treatment of the situation when $P_{t}>P_{c}$ is required. That is, a temporary shut-off of fuel ejection appears to be physically reasonable, as described in this report. However, it requires the treatment of the interaction region entering the inside of a pin. 
(iii) In view of the up-coming experiment $\mathrm{AX}-1$, a pretest analysis requires the treatment of fuel vapor as the ejection mechanism. This may require a redefinition of what is conventionally considered as interaction between two liquids and a consideration of the fuel-vapor/liquid-sodium interface.

of final interest is the comparison of the results obtained in this report with the SAS/FCI results. The SAF/FCI-induced void reactivity rates in the carbide core accident involvement were predicted to be $2-4$ times higher than those in one equivalent oxide core. ${ }^{2}$ These relative differences were obtained from subassembly averaging. The single comparison (case 1 and case 2) done with PLUTO predicts that the void reactivity rates in carbide will be 5.5 times higher than in oxide. Despite the differences in the models (SAS/FCI and PLUTO), and that the SAS/FCI has been used in the integrated fashion, the results seem in surprising agreement. Aside from the model differences, physically, one would expect a lower reactivity rate in the whole core accident involvement due to the pressurization of the inlet plenum, which enhances an. upward translation of the interaction zone, and due to the above-core-midplane clad failure locations. 


\section{REFERENCES}

1. Wider, H. U., "An Improved Analysis of Fuel Motion during an Overpower Excursion," Ph.D. Thesis, Northwestern University (1974).

2. Mync, L., Bowers, C. H.,-Ferguson, D. R., "Analysis of Core Disruptive Accidents in Carbide-Fueled LMFBR," Int1. Meeting on Advanced LMFBR Fuels, Tucson, Arizona, ERDA-4455 pp. 389-406, October, 1977.

3. Mync, L., et. a1., "Identification of Model Development Needs for Carbide Fueled LMFBRs through the Use of SAS Parametrics," ANL/AFP report, to be issued (1977).

4. Hinze, U. O., "Forced Deformation of Viscous Liquid Globules," Applied Scientific Research, Vol. Al, The Hauge, 1949, pp. 263-272.

5. Swift, D., Baker, L., "Experimental Studies of the High Temperature Interastion of Fiel and Cladding Matcrlal with Liquid Büdlum," Proc. Conf. Safety Fuels, and Core Design in Large Fast Power Reactors, ANL7120, October 11-14, 1965, pp. 839-947.

6. Cho, D. H., "Modeling of Fue1-Coolant Interaction Zone Processes for Advanced Fuels," Advanced Fuels Quarterly Report for the period January March, 1977, ANL/AFP-35, pp. 203-206.

7. Hsiao, K. M., et. al., "Pressurization of Solidifying Sphere," J. App. Mech. 39, pp. 7177, 1972.

8. Flory, R., "Molten Metal Water Explosions," Chem. Eng. Progr., 65, pp. $50-54,1969$.

9. Smith, L. L., et. al., "SAS/FCI: The SAS3A Fuel-Coolant Interaction Mode1," ANL/RAS 75-23, December 1975.

10. Wider, H. U. and Wright, A. E., "Analysis of a Sodium Reentry Event in the H9 TREAT Test," Tanso 22, pp. 428 (1975).

11. Rothman, A. B., et. a1., "Results of Recent TOP and LOF Experiments in TREAT," Fast Reactor Safety Meeting, (Chicago, 1976). 
Table 1

Geometry, Fuel Properties, Initial and Boundary Conditions, for the Carbide/Oxide Comparison

Geometry

Pin diameter (cm)

Coolant flow area $\left(\mathrm{cm}^{2}\right)$ (per pin)

Hydraulic diameter $(\mathrm{cm}) \quad\left\{\begin{array}{l}\text { core and } \mathrm{f} \cdot \mathrm{g} \cdot \mathrm{plenum} \\ \text { upper sub assembly structure* } \\ \text { lower subassembly structure* }\end{array}\right.$

Axial dimensions (see fig. 1)

Fuel Properties ${ }^{+\dagger}$

Melting temperature $\left({ }^{\circ} \mathrm{K}\right)$

Thermal conductivity (W/cm sec ${ }^{\circ} \mathrm{K}$ )

Specific heat $\left(j . / \mathrm{gm} .{ }^{\circ} \mathrm{K}\right)$

Physical density $\left(\mathrm{gm} / \mathrm{cm}^{3}\right)$

Heat of fusion $\left(\mathrm{j} / \mathrm{gm}^{\circ} \mathrm{K}\right)$

\section{Initial Conditions}

Fuel pin cavity temperature $\left({ }^{\circ} \mathrm{K}\right)$

Cladding temperature $\left({ }^{\circ} \mathrm{K}\right)$

Inlet sodium temperature $\left({ }^{\circ} \mathrm{K}\right)$

outlet sodium temperature $\left({ }^{\circ} \mathrm{K}\right)$

Mass of fission gas/mass of fuel in the cavity ${ }^{* *}$

Fuel smear density in pin cavity $\left(\mathrm{gm} / \mathrm{cm}^{3}\right)$

Inlet pressure (atm) ${ }^{\dagger}$

Outlet pressure (atm) $\dagger$

Sodium velocity $(\mathrm{cm} / \mathrm{sec}$.)

Fuel particle radius $(\mathrm{cm})$

Initial mass of ejected fuel (gm)

Pin cavity pressure prior to fuel ejection (atm)

Mass of sodium at rupture location-

Lagrangian node at $R_{0}$ (gm)
Carbide

Oxide

0.9525

0.5740

0.68

0.71

0.79
0.7620

0.2582

0.39

0.45

0.32

$\begin{array}{ll}\quad 2758 & 3033 \\ 0.197 & 0.0243 \\ 0.296 & 0.502 \\ 8.79 & 8.56 \\ 186 & 282\end{array}$

*

The values for lower and upper subassembly structures were chosen so as to match sodium pressure drops to those of $\mathrm{SAS}^{3}$ predictions prior to clad failure.

$\star *$

The flssion gas content was chosen in order to achieve equal ejection pressure from both pins.

t Strictly speaking, the specification of inlet and outlet pressure is a boundary condition.

tt Properties of fuels are evaluated at their respective temperatures. 
Table 2

Transient Results for Cases 1 and 2

\section{Case 1}

Time Fuel temp. Void fraction Na temp. Na vapor press. Fission-gas press.

\begin{tabular}{|c|c|c|c|c|c|c|c|c|c|c|}
\hline & sec & 3077 & ${ }^{\circ} \mathrm{K}$ & 0.0 & 996 & & 0.191 & atm & 178. & atm \\
\hline 2 . & $"$ & 2754 & ${ }^{\circ} \mathrm{K}$ & 0.009 & 1278 & $\cdot \mathbf{K}$ & 2.68 & $"$ & 53.8 & $"$ \\
\hline 4 & $"$ & 2756 & $\because_{\mathrm{K}}$ & 0.18 & 1749 & ${ }^{\cdot} \mathrm{K}$ & 34. & $"$ & 14.1 & $"$ \\
\hline 6 & $"$ & 2757 & ${ }^{\circ} \mathrm{K}$ & 0.55 & 1927 & ${ }^{\cdot} \mathrm{K}$ & 65. & $"$ & 0.63 & $"$ \\
\hline 8 & $"$ & 2757 & $\cdot \mathrm{k}$ & 0.70 & 1854 & ${ }^{\cdot} \mathrm{K}$ & 51. & $"$ & 0.31 & $"$ \\
\hline 10 & $"$ & 2758 & $\cdot \mathrm{K}$ & 0.76 & 1747 & $\cdot \mathrm{K}$ & 34.2 & $"$ & 0.41 & $"$ \\
\hline 12 & $"$ & 2791 & ${ }^{*} \mathrm{~K}$ & 0.16 & 1595 & $\cdot \mathrm{K}$ & 18.0 & $"$ & 0.84 & $"$ \\
\hline 14 & $"$ & 2925 & $\cdot \mathrm{K}$ & 0.58 & 1452 & ${ }^{\circ} \mathrm{K}$ & .8 .48 & $"$ & 1.78 & $"$ \\
\hline 26 & $"$ & 3046 & ${ }^{\circ} \mathrm{K}$ & 0.49 & 1151 & $\cdot \mathrm{K}$ & 0.97 & $"$ & 2.22 & $"$ \\
\hline 50 & $"$ & 3070 & ${ }^{\circ} \mathrm{K}$ & 0.63 & $1151:$ & $\cdot \mathrm{K}$ & 0.97 & $"$ & 0.72 & $"$ \\
\hline 80 & $"$ & 3074 & $\cdot \mathrm{K}$ & 0.76 & 1151 & $\cdot \mathrm{K}$ & 0.97 & $"$ & 0.51 & $"$ \\
\hline .00 & $"$ & 3073 & $\cdot \mathrm{K}$ & 0.83 & 1151 & $\cdot \mathrm{K}$ & 0.97 & $"$ & 0.67 & $"$ \\
\hline
\end{tabular}

Case 2

\begin{tabular}{|c|c|c|c|c|c|c|c|c|c|}
\hline 0 & $"$ & 3290 & ${ }^{\circ} \mathrm{K}$ & 0.0 & 944 & ${ }^{\circ} \mathrm{K}$ & 0.098 & $"$ & 197. \\
\hline 2 & $"$ & 3236 & ${ }^{\cdot} \mathrm{K}$ & 0.014 & 1022 & $\cdot \mathrm{K}$ & 0.26 & $"$ & 64. \\
\hline 4 & $"$ & 3227 & ${ }^{\circ} \mathrm{K}$ & 0.087 & 1179 & $\cdot \mathrm{K}$ & 1.23 & ". & 21. \\
\hline b & $"$ & 3230 & $\cdot \mathrm{K}$ & 0.17 & 1317 & $\cdot \mathrm{K}$ & 3.60 & " & 13.9 \\
\hline 8 & $"$ & 3238 & ' $\mathrm{K}$ & 0.23 & 1325 & $\cdot \mathrm{K}$ & 3.84 & " & 11.1 \\
\hline $10^{\prime}$ & $"$ & 3251 & ${ }^{\circ} \mathrm{K}$ & 0.26 & 1224 & $\cdot \mathrm{K}$ & 1.81 & $"$ & 10.4 \\
\hline $12^{\prime}$ & $"$ & 3257 & • $\mathrm{K}$ & 0.27 & 1109. & $\cdot \mathrm{K}$ & 0.66 & $"$ & $10: 1$ \\
\hline $14^{\prime}$ & $"$ & 3264 & $\cdot \mathrm{K}$ & 0.35 & 1046 & ${ }^{\circ} \mathrm{K}$ & 0.34 & " & 9.1 \\
\hline $26^{\prime}$ & $"$ & 3283 & $\cdot \mathrm{K}$ & 0.44 & 955 & $\cdot \mathrm{K}$ & 0.11 & $"$ & 5.6 \\
\hline $50^{\prime}$ & " & 3286 & $\cdot \mathrm{K}$ & 0.41 & 952 & $\cdot \mathrm{K}$ & 0.11 & $"$ & 3.8 \\
\hline $80^{\prime}$ & " & 3226 & ${ }^{\circ} \mathrm{K}$ & 0.34 & 994 & $\cdot \mathrm{K}$ & 0.19 & ." & 3.2 \\
\hline $100^{\prime}$ & $"$ & 3035 & $\cdot \mathrm{K}$ & 0.47 & 1097 & ' $\mathrm{K}$ & 0.58 & $"$ & 4.82 \\
\hline
\end{tabular}


$\underline{\text { Table } 4}$

An Over-View of the Parametric Study Normalized to the OFCI (case 2)

\begin{tabular}{|c|c|c|c|c|}
\hline Parameter & OFCI (case 2) & CFCI (case i) & $\begin{array}{l}\text { Ejection of oxide } \\
\text { into carbide coolant } \\
\text { channel (case } 3 \text { ) }\end{array}$ & $\begin{array}{l}\text { Ejection of carbide } \\
\text { into oxide channel } \\
\text { (case 4) }\end{array}$ \\
\hline $\begin{array}{l}\text { 1. Average rise in sodium } \\
\text { temperature } \mathrm{T}_{\mathrm{Na}}\end{array}$ & {$\left[4.76 \times 10^{3 \circ} \mathrm{K} / \mathrm{sec}\right]$} & 3.3 & 0.9 & 5.6 \\
\hline $\begin{array}{l}\text { 2. Maximum sodium vapor } \\
\text { pressure at } R_{0}\end{array}$ & {$\left[\begin{array}{c}1 \\
4\end{array}\right.$} & 16.3 & 1.8 & 17.8 \\
\hline $\begin{array}{l}\text { 3. Maximum size of the } \\
\text { interaction region : }\end{array}$ & {$\left[118^{1} \mathrm{~cm}\right]$} & 1.9 & 0.9 & 1.4 \\
\hline $\begin{array}{l}\text { 4. Maximum sodium void } \\
\text { reactivity } \rho_{\mathrm{Na}}\left(t_{\rho}\right)\end{array}$ & . & 3.3 & 2.0 & 1.5 \\
\hline $\begin{array}{l}\text { 5. Average sodium void } \\
\text { reactivity rate } \\
\rho_{\mathrm{Na}}\left(t_{p}\right) / t_{p}\end{array}$ & $1:$ & 5.5 & 1.8 & 1.5 \\
\hline $\begin{array}{l}\text { 6. Mass of initially } \\
\text { ejected fuel }\end{array}$ & {$[0.16 \mathrm{gm}]$} & 2.1 & 2.1 & 1.0 \\
\hline $\begin{array}{l}\text { 7. Total-transient mass } \\
\text { of fuel ejected }\end{array}$ & {$\left[62^{1} \mathrm{gm}\right]$} & 1.4 & 1.3 & 1.1 \\
\hline $\begin{array}{l}\text { 8. Minimum position of } \\
\text { the interaction zone } \\
\text { min. }(\mathrm{L}(\mathrm{z}, t)) \\
t\end{array}$ & {$\left[65^{1} \mathrm{~cm}\right]$} & 0.1 & 1.0 & 0.5 \\
\hline $\begin{array}{l}\text { 9. Assymmetry of the } \\
\text { interaction zone } \\
\text { (at } t=50 \text { ms.) }\end{array}$ & 1 & 0.45 & .1 .3 & 0.53 \\
\hline $10 \begin{array}{l}\text { Time at which } \mathrm{L}^{-} \\
\text {resumes upward } \\
\text { motion }\end{array}$ & {$\left[46^{1} \mathrm{~ms}\right]$} & 1.48 & 1.00 & 1.34 \\
\hline $\begin{array}{l}\text { 11. Time at which } \mathrm{L}^{+} \text {reaches } \\
\text { the upper ax.blanket/core } \\
\text { interface }\end{array}$ & {$\left[34^{1} \mathrm{~ms}\right]$} & $0.53^{\circ}$ & 0.90 & 0.53 \\
\hline
\end{tabular}




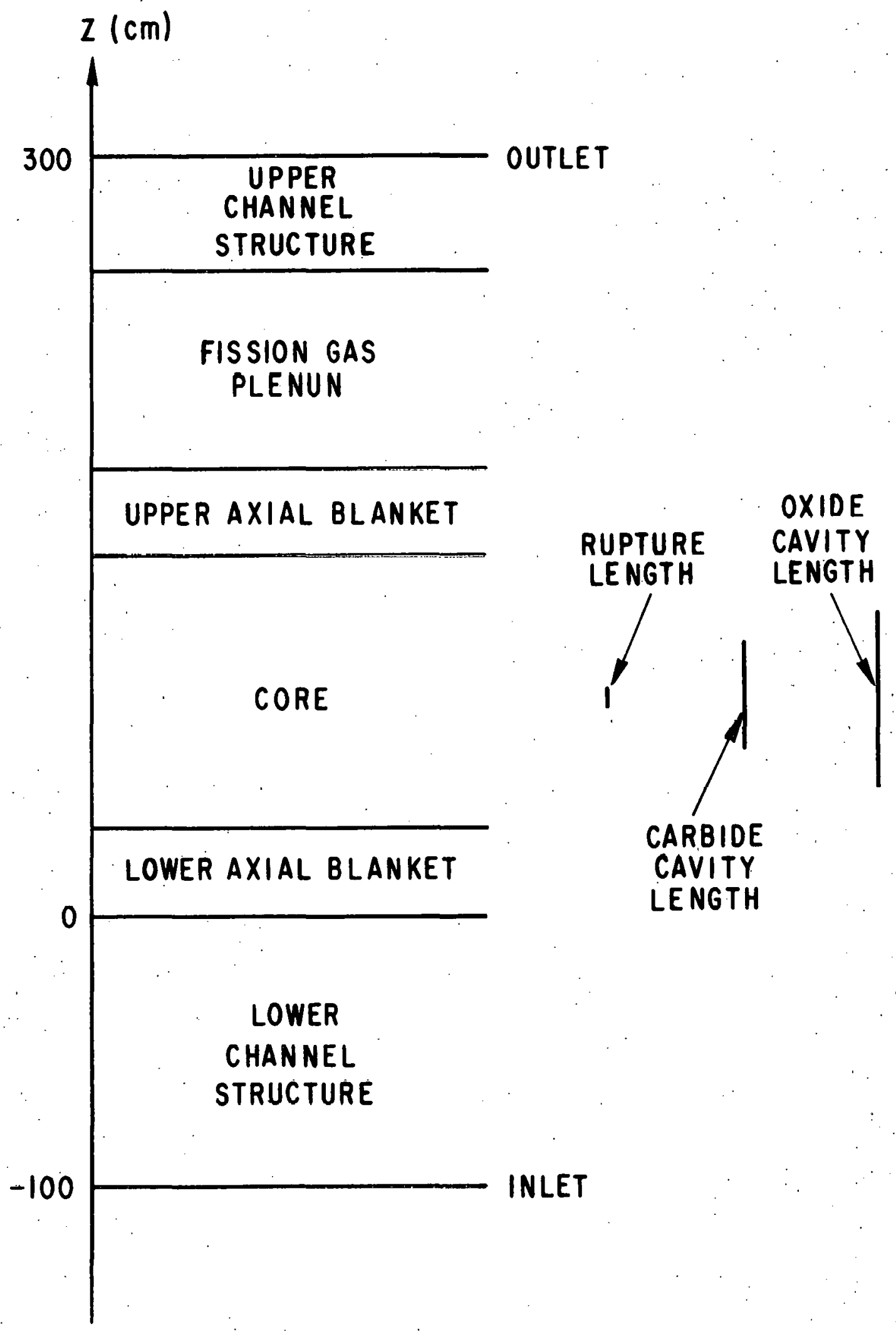

Fig. 2. Axial Geometry. 


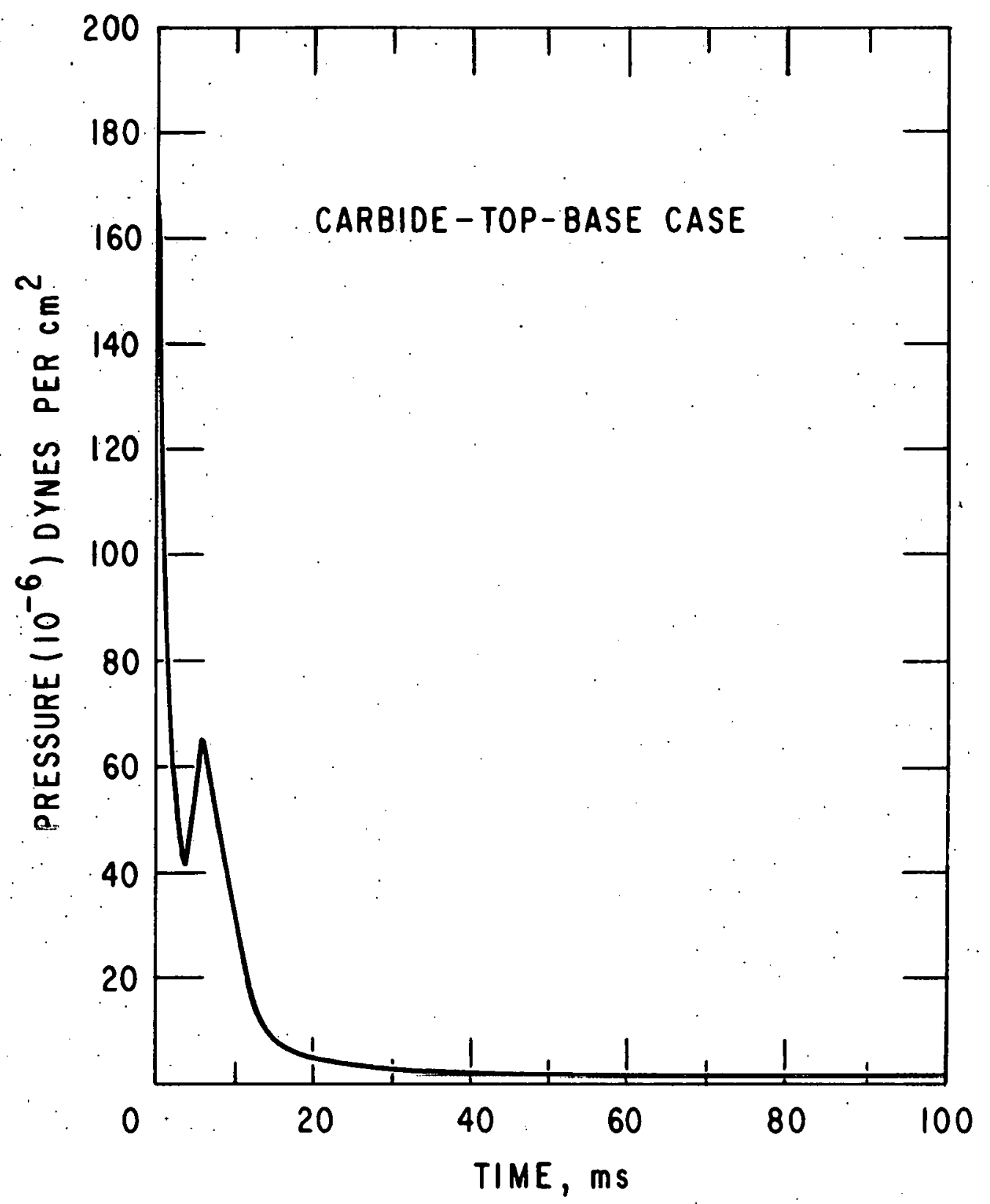

Fig. 3. Pressure History at : $\mathrm{o}_{0}$ for Case 1. 


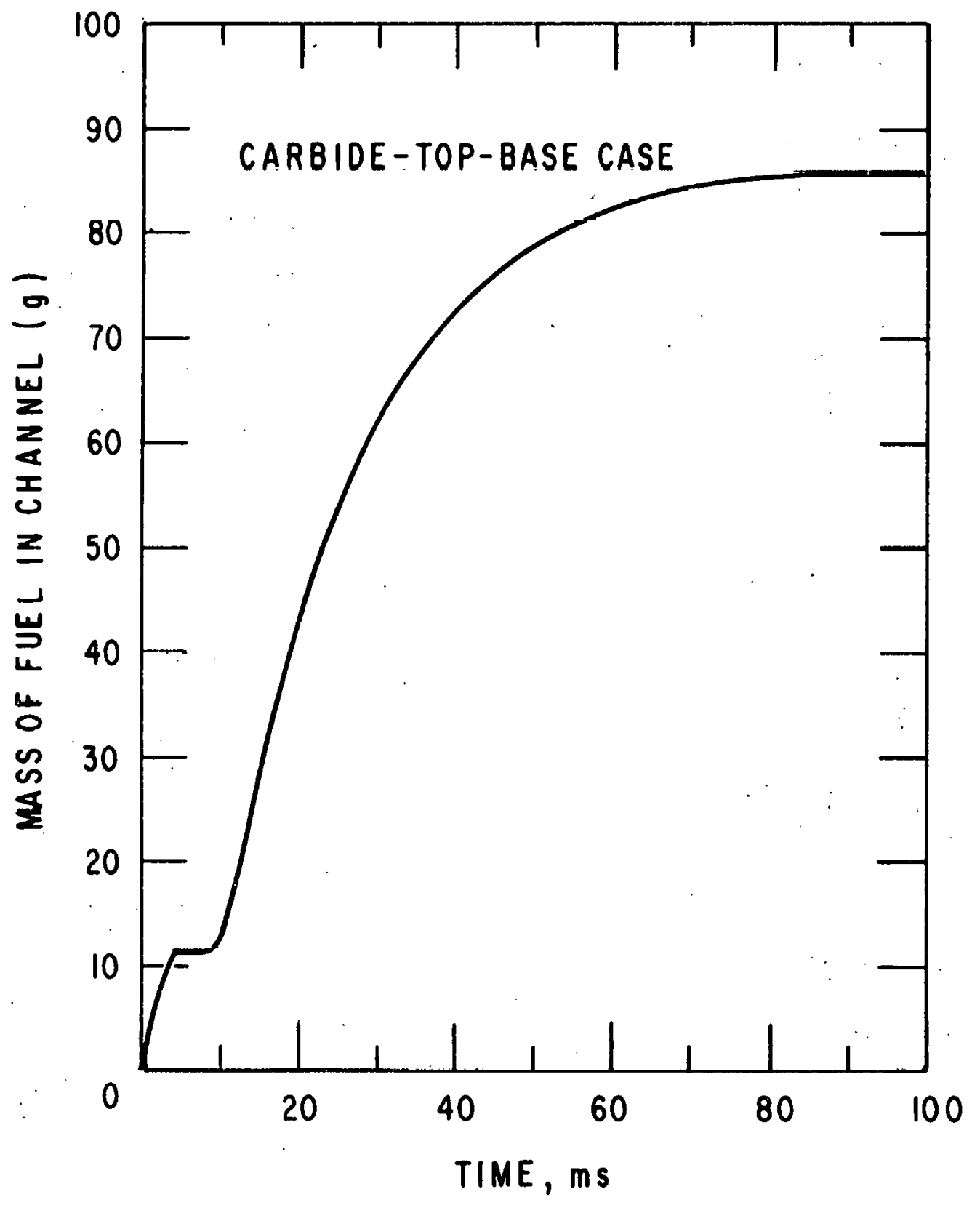

Fig. 4. Mass of Carbide Ejected (Case 1). 


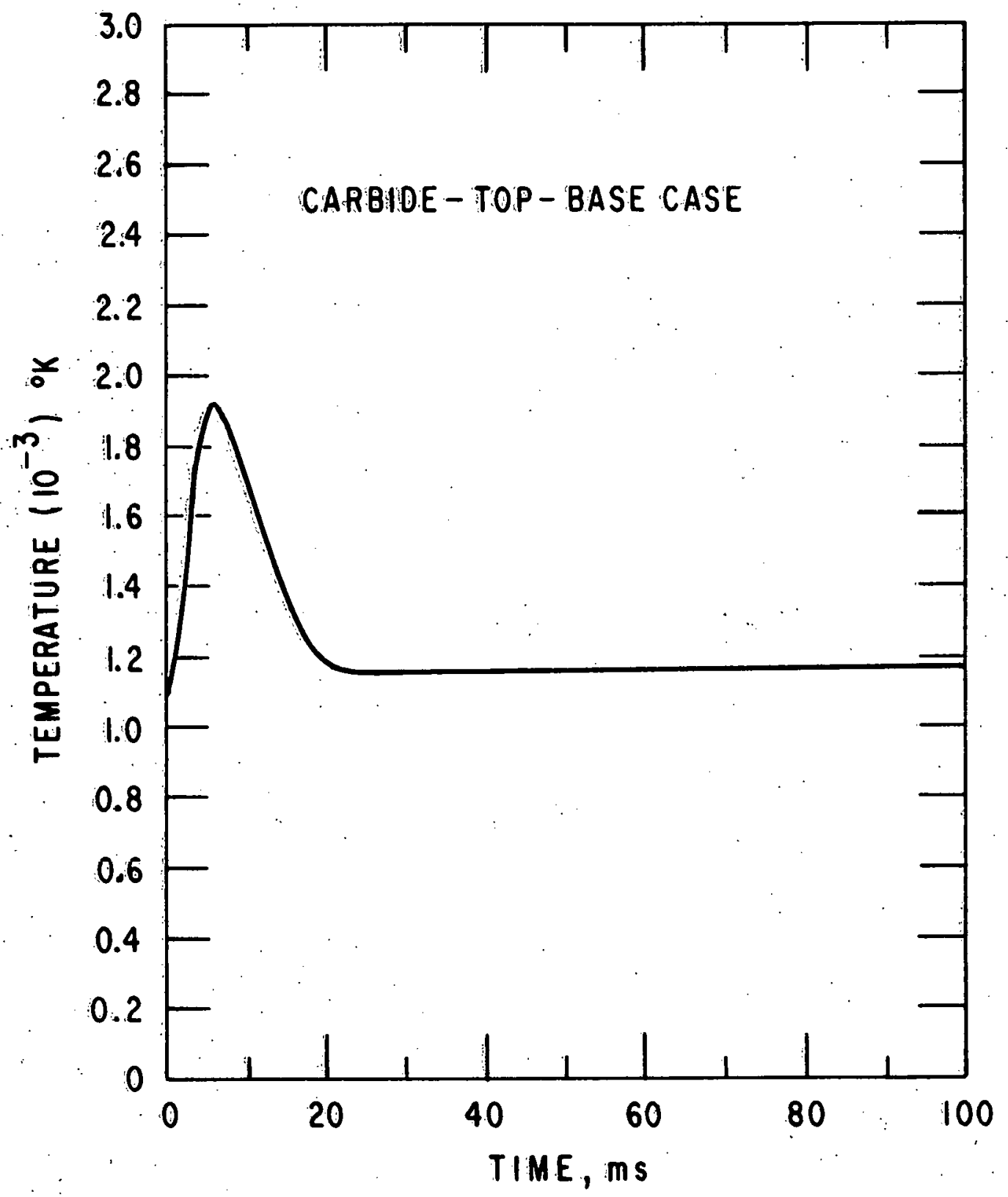

Fig. 5. Sodium Temperature at $R_{0}$ for Case 1. 


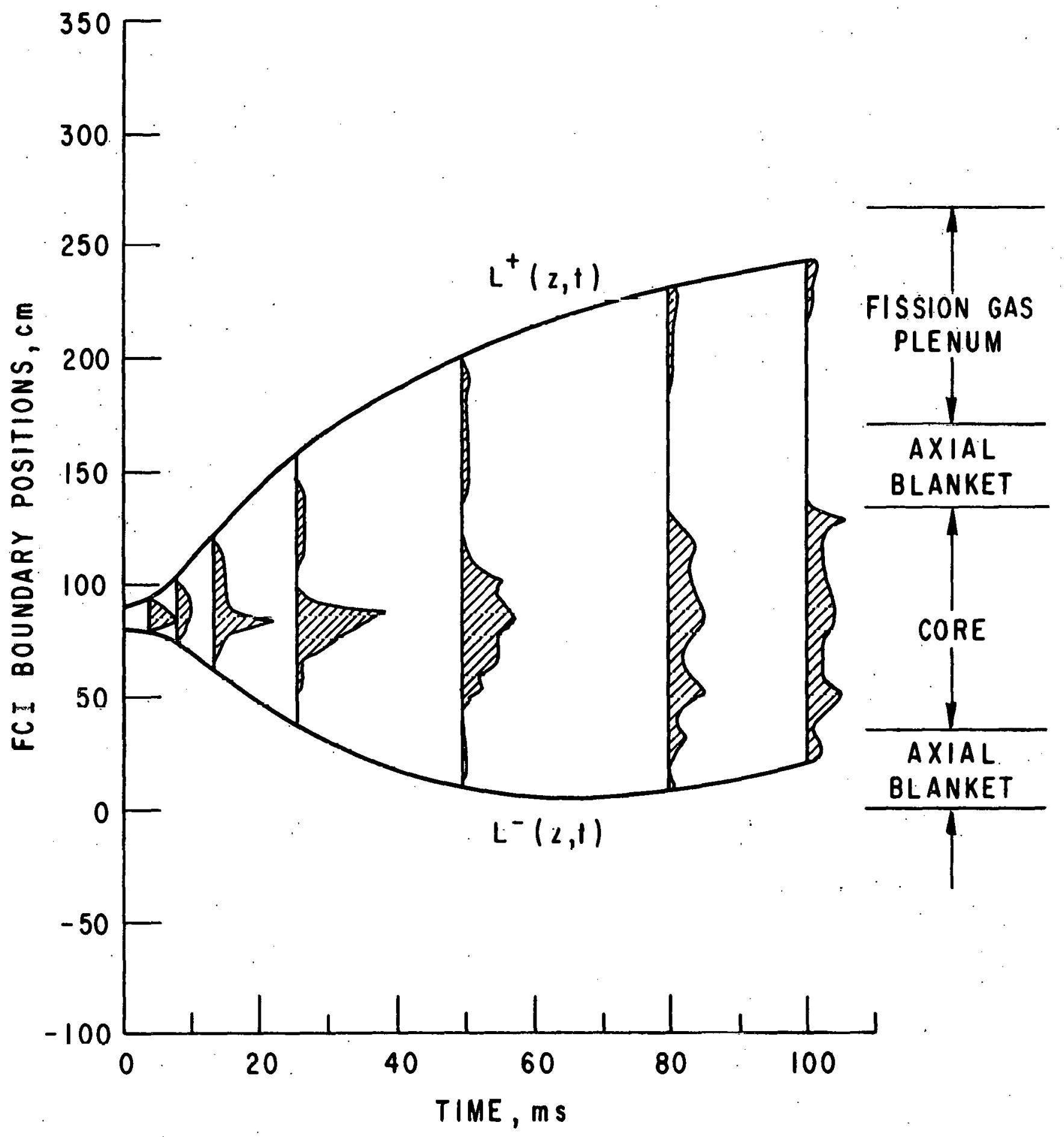

Fig. 6. Extent and Shape (at $t=5,8,15,25$, 50,80 , and $100 \mathrm{~ms}$ ) of Carbide Distributions ( $\mathrm{L}^{+}$and $\mathrm{L}^{-}$interfaces) (Case 1). Shaded areas illustrate the nurmalized fuel distribution. 


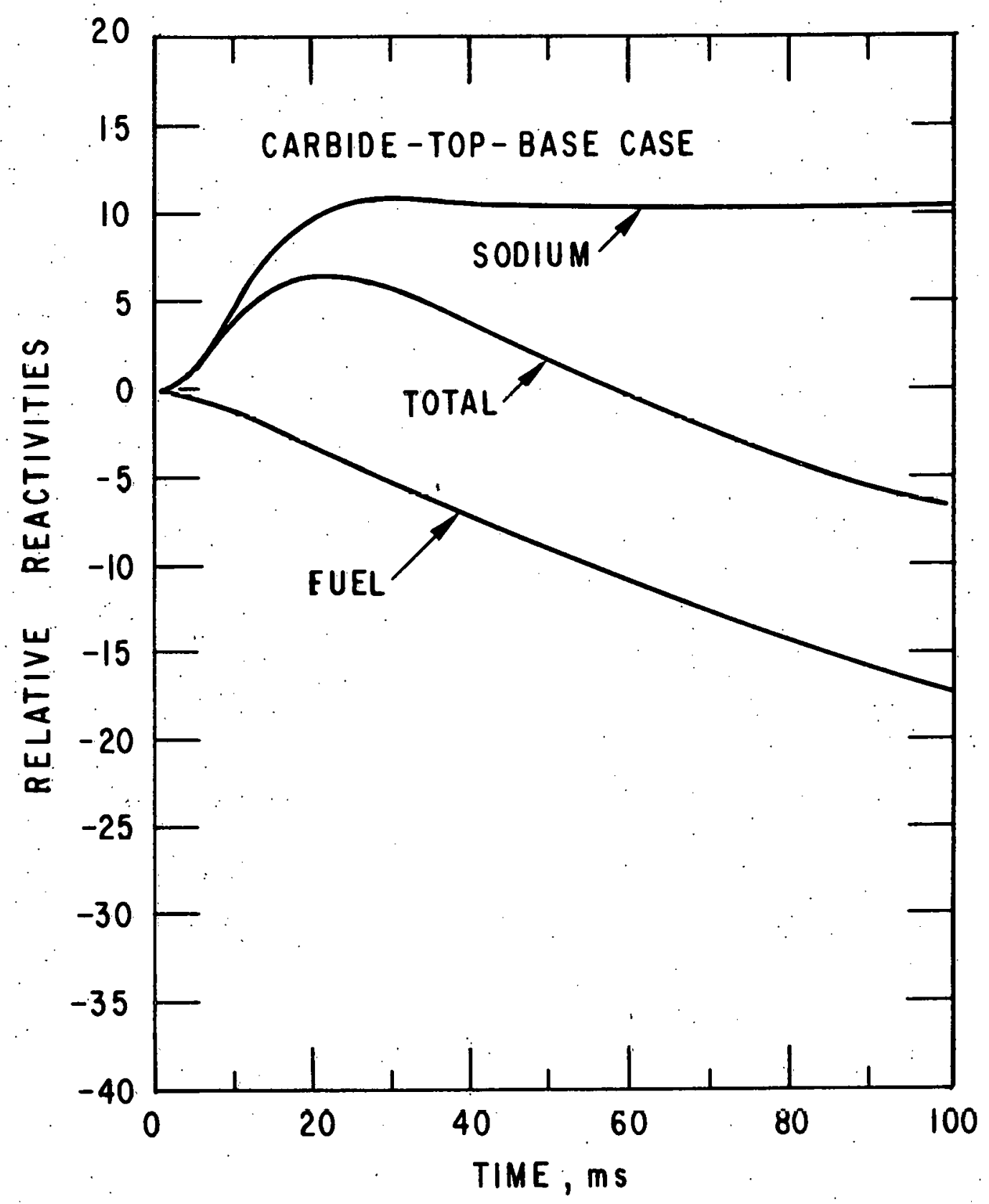

Fig. 7. Reactivity History for Case 1. 


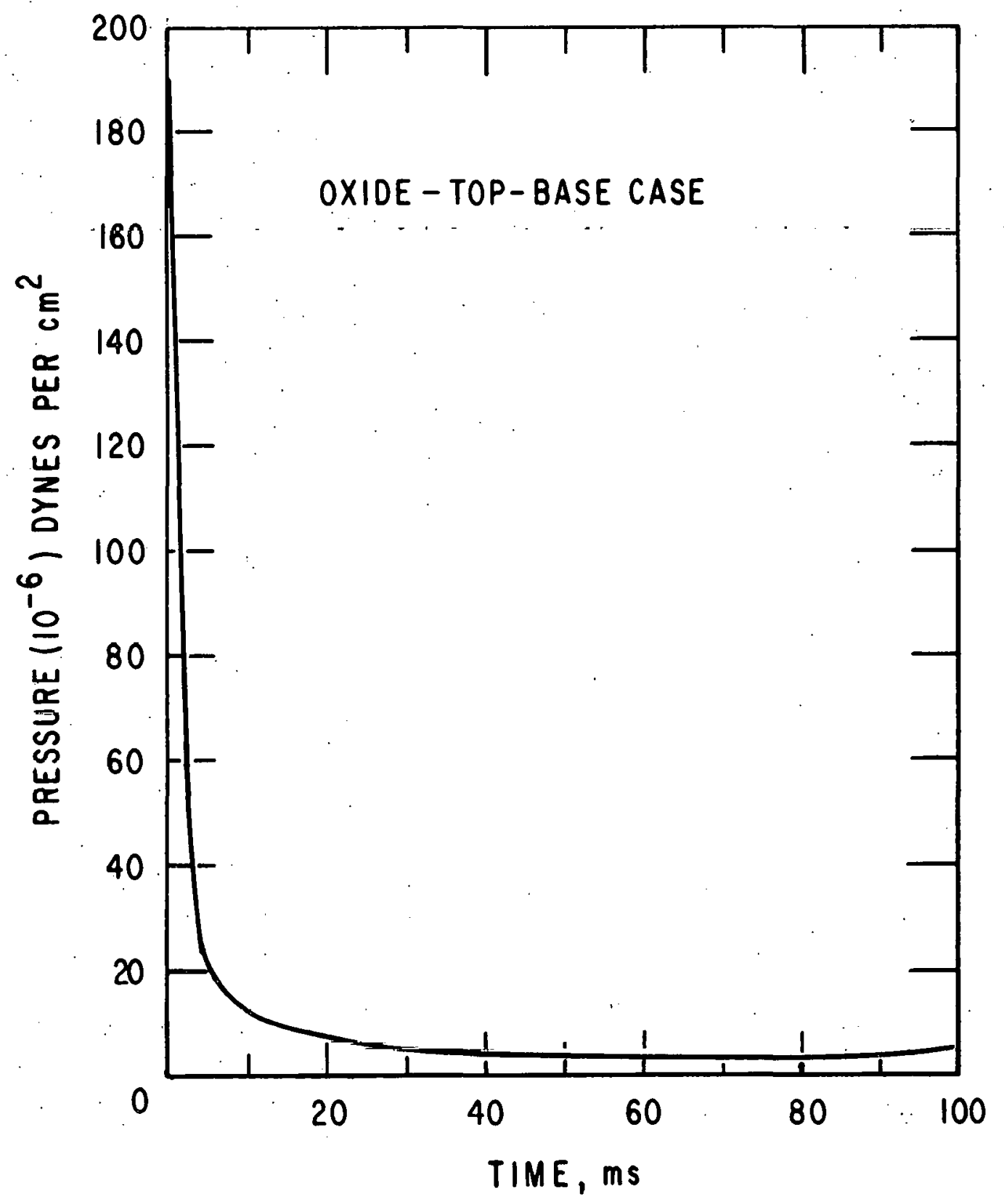

Fig. 8. Pressure History at $\mathrm{R}_{\mathrm{o}}$ for Case 2. 


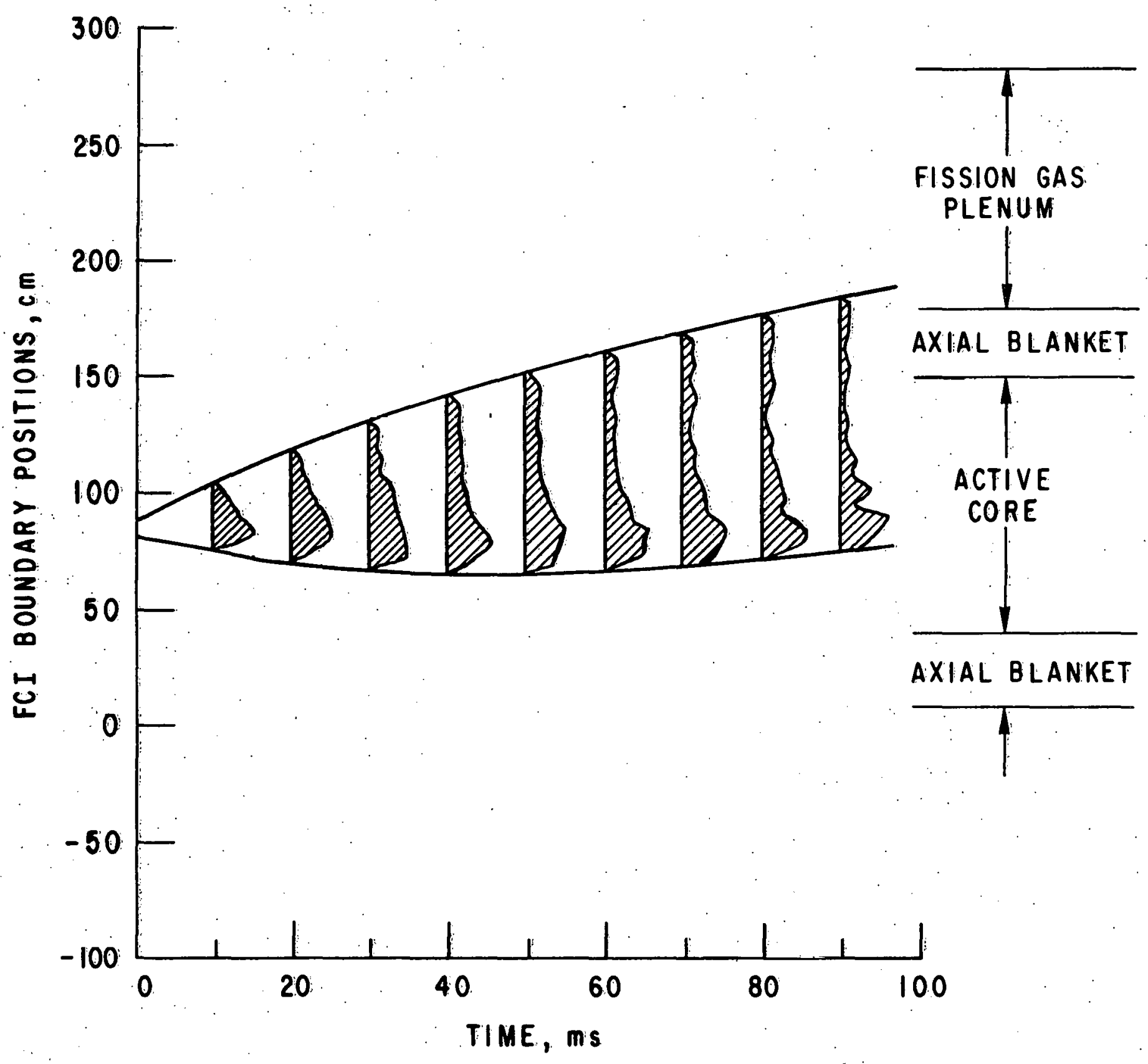

Fig. 9. Extent of the Interaction Zone for Oxtde (Case 2). Shaded areas illustrate the distribution of ejected oxide. 


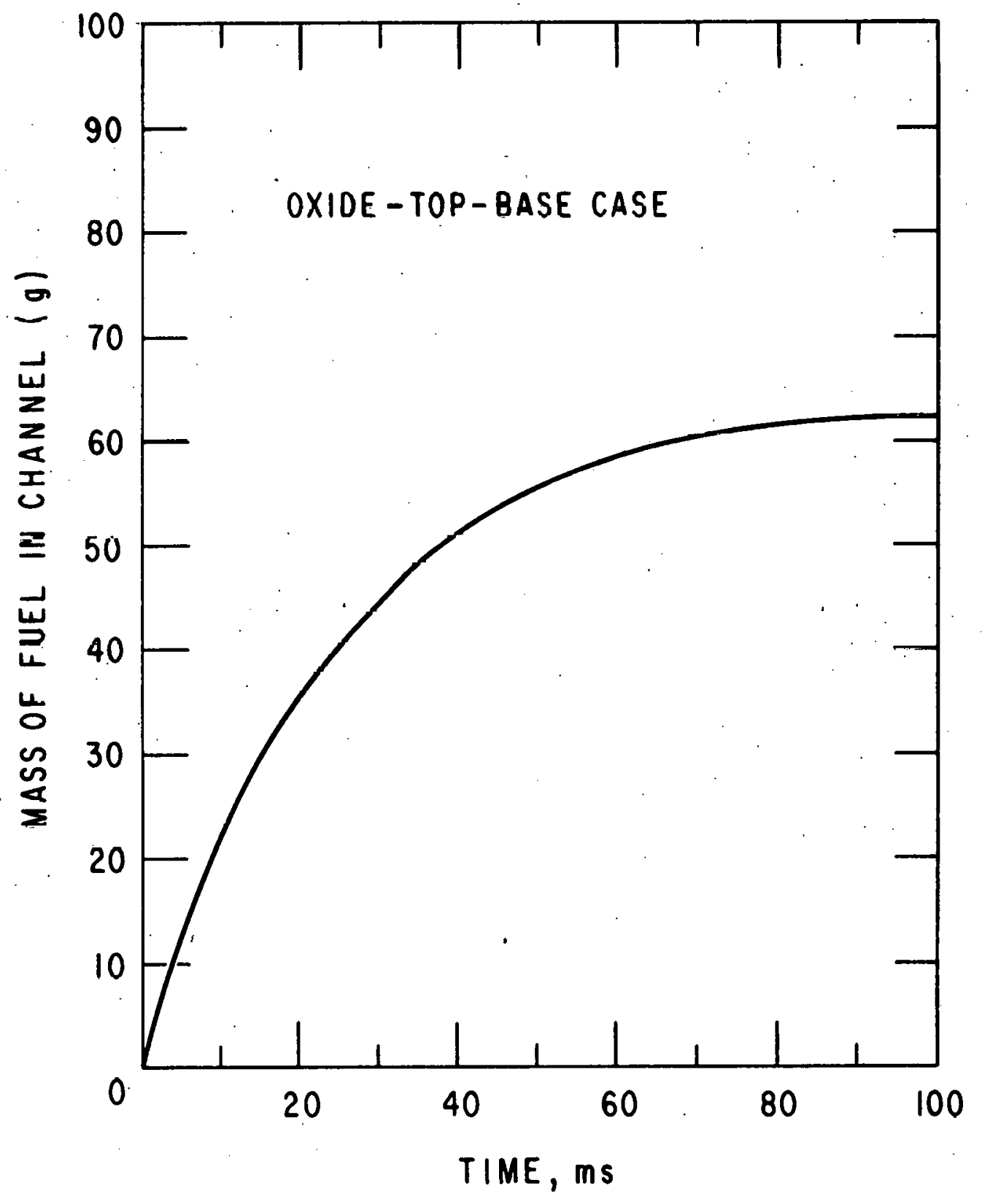

Fig. 10. Mass of Oxide Ejected (Case 2). 


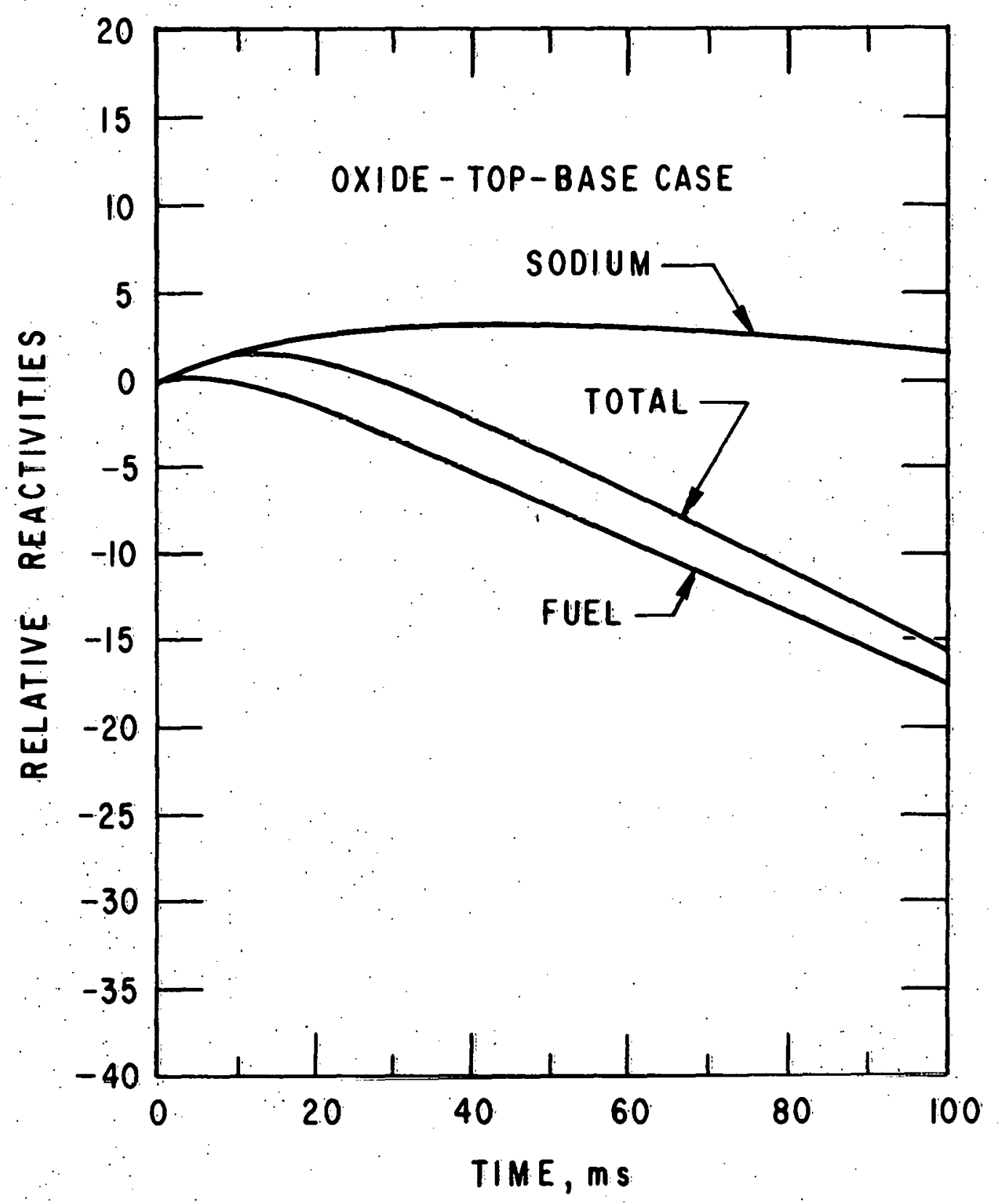

Fig. 11. Reactivity History for Case 2 . 


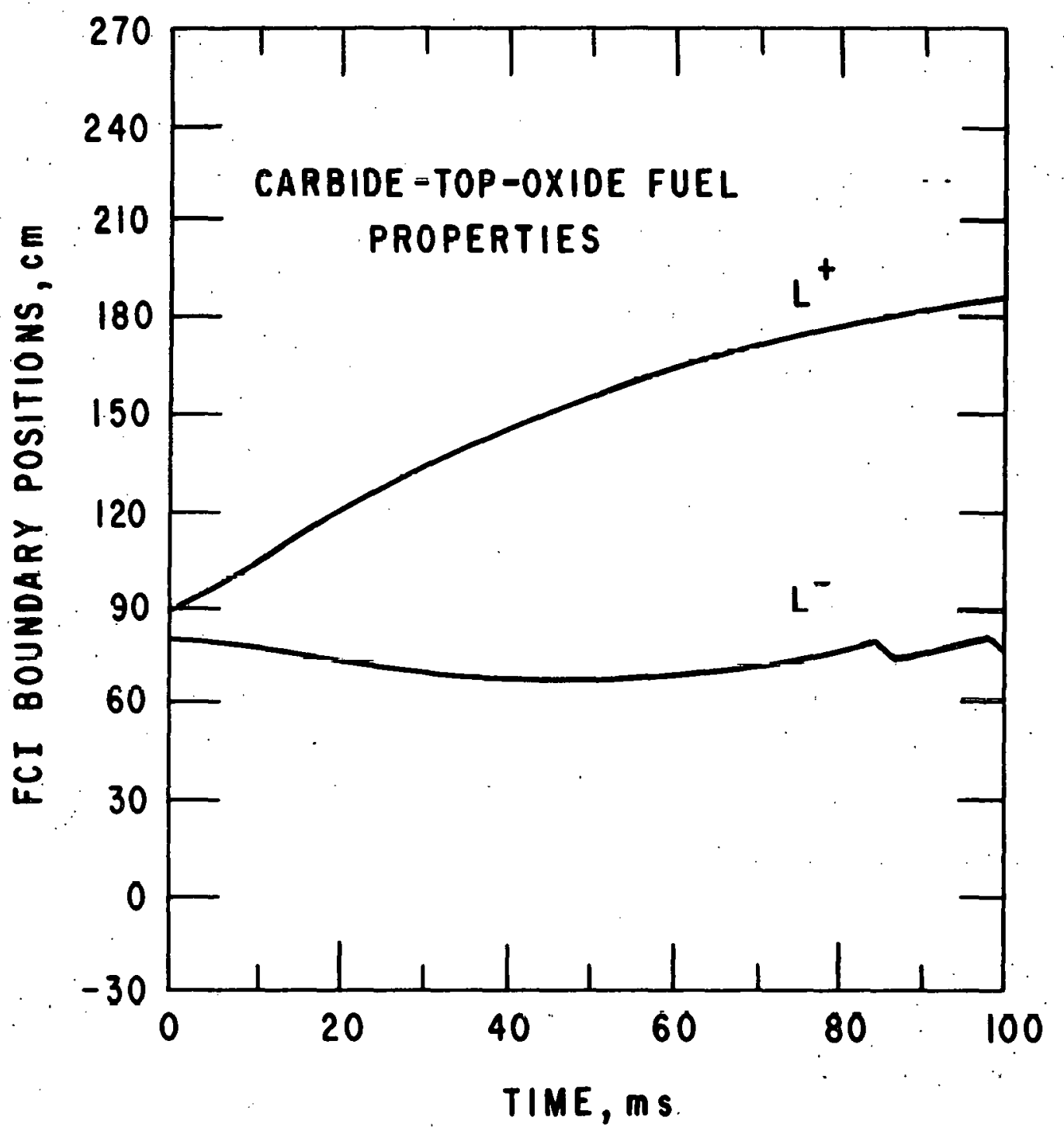

Fig. 12. Extent of the Interaction Zone for Case 3 . 


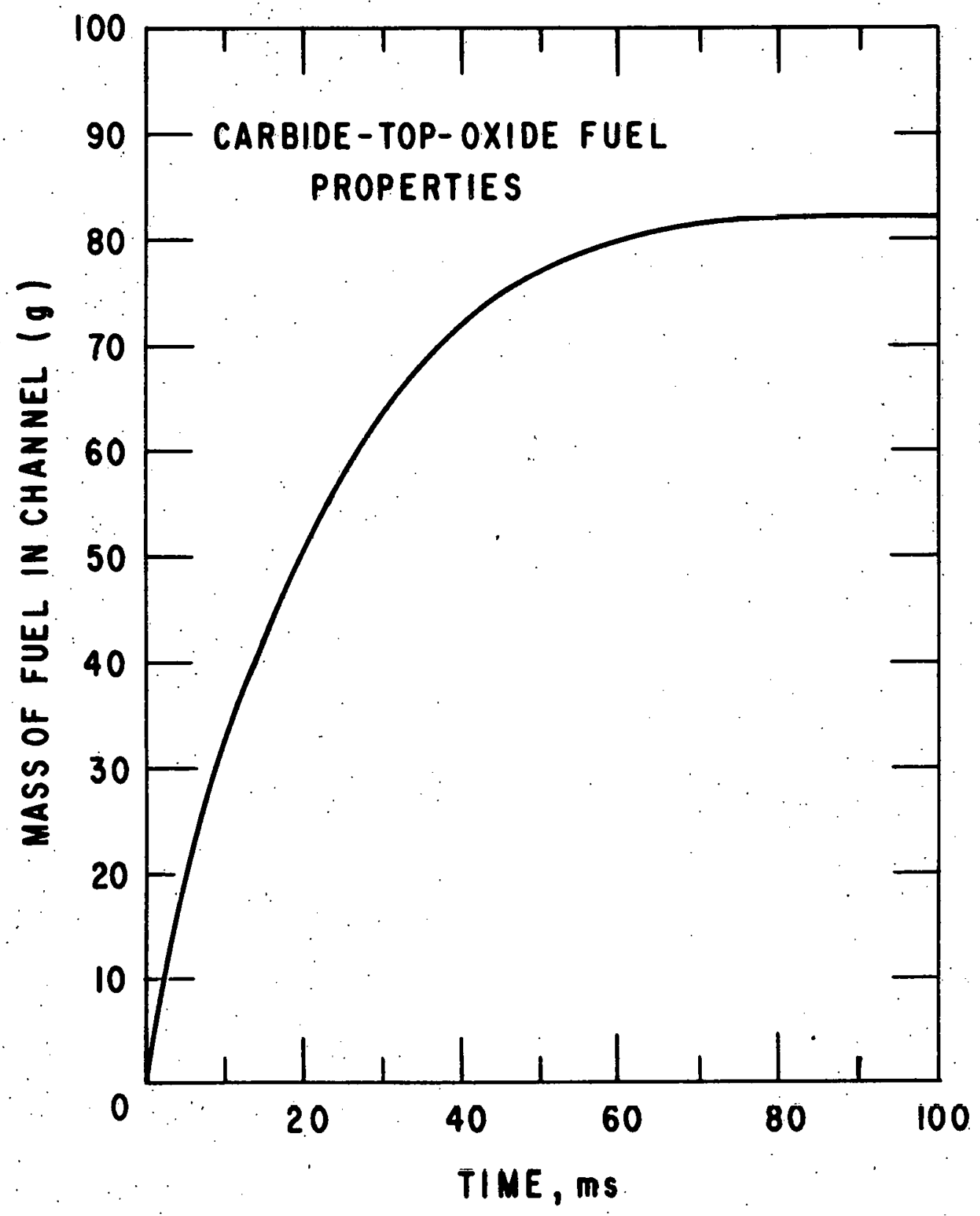

Fig. 13. Mass of Ejected Oxide (Case 3). 


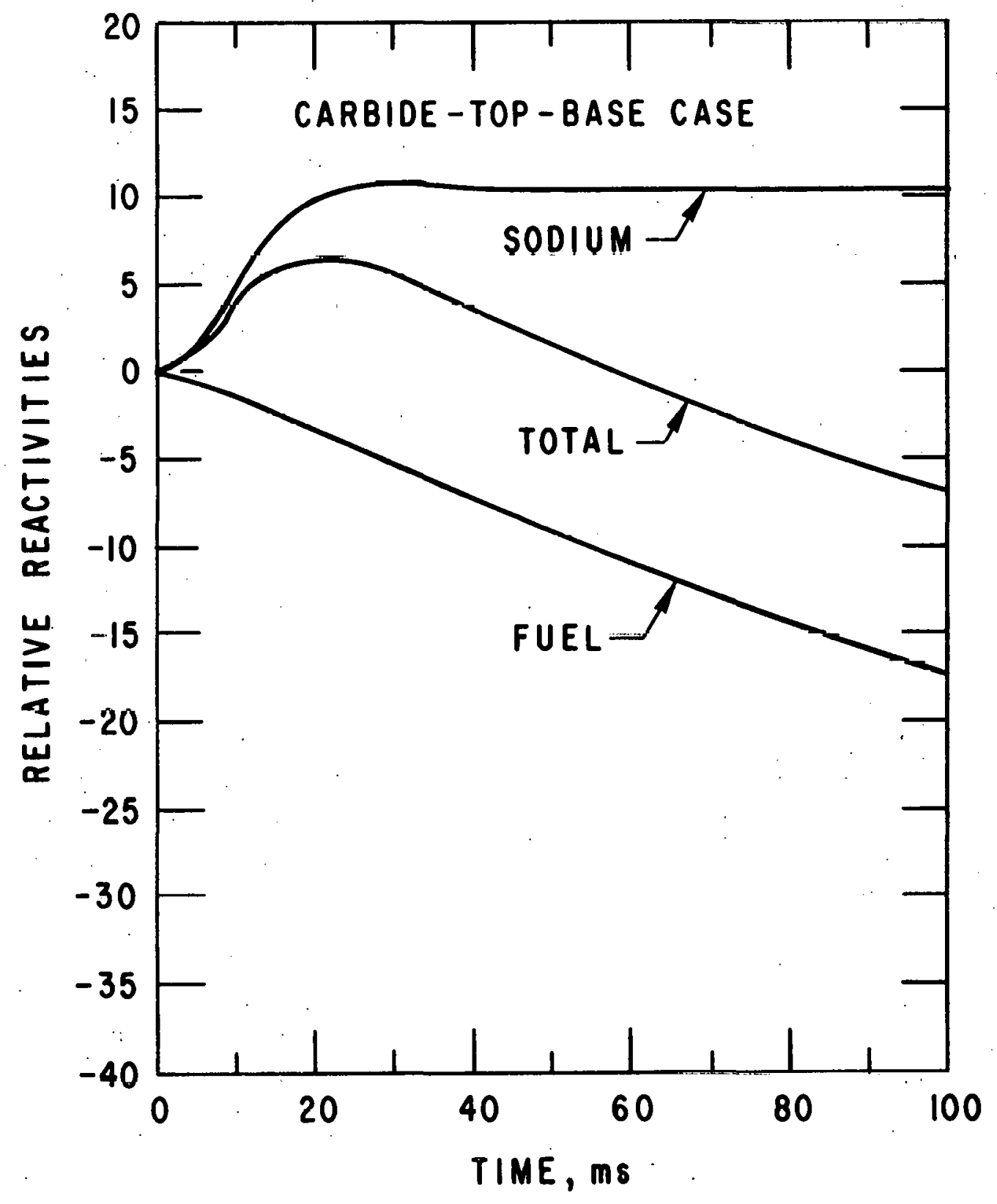

Fig. 14a. Comparison of Reactivity Effects in Case 1. 


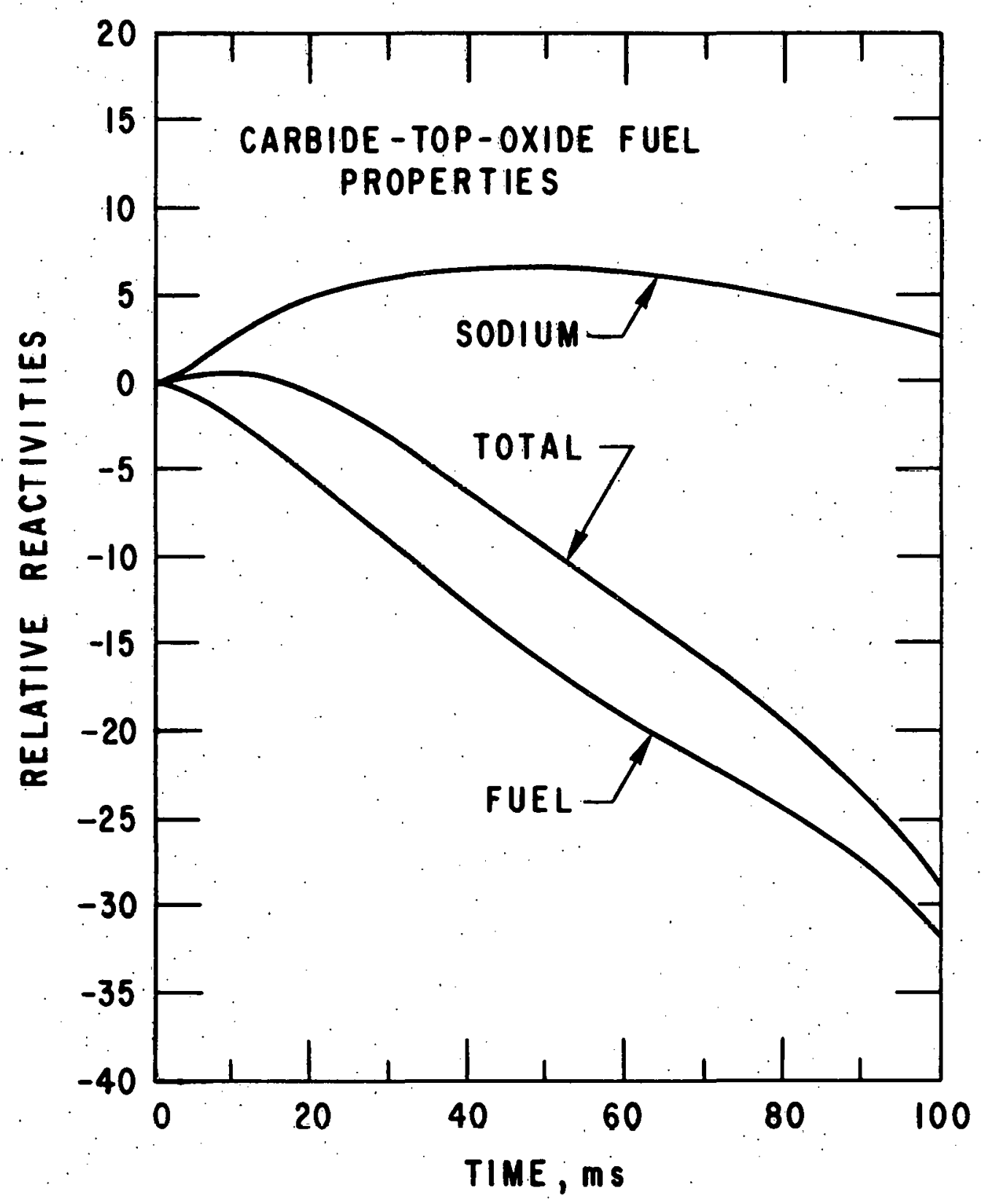

Fig. 1/b. Comparison of Reactivity Effects in Case 3. 


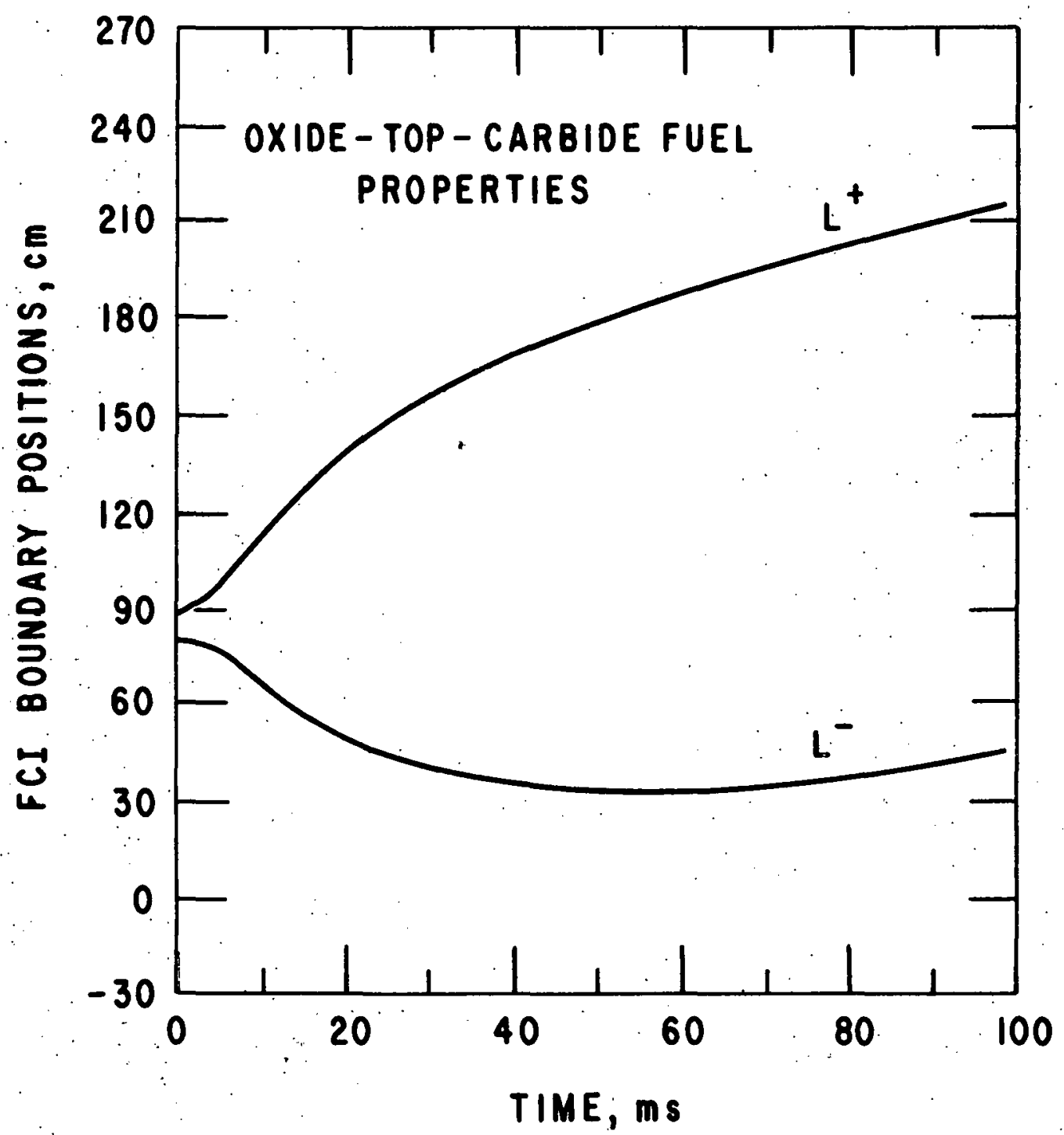

Fig. 15. Development of Interaction Zone in Case 4. 


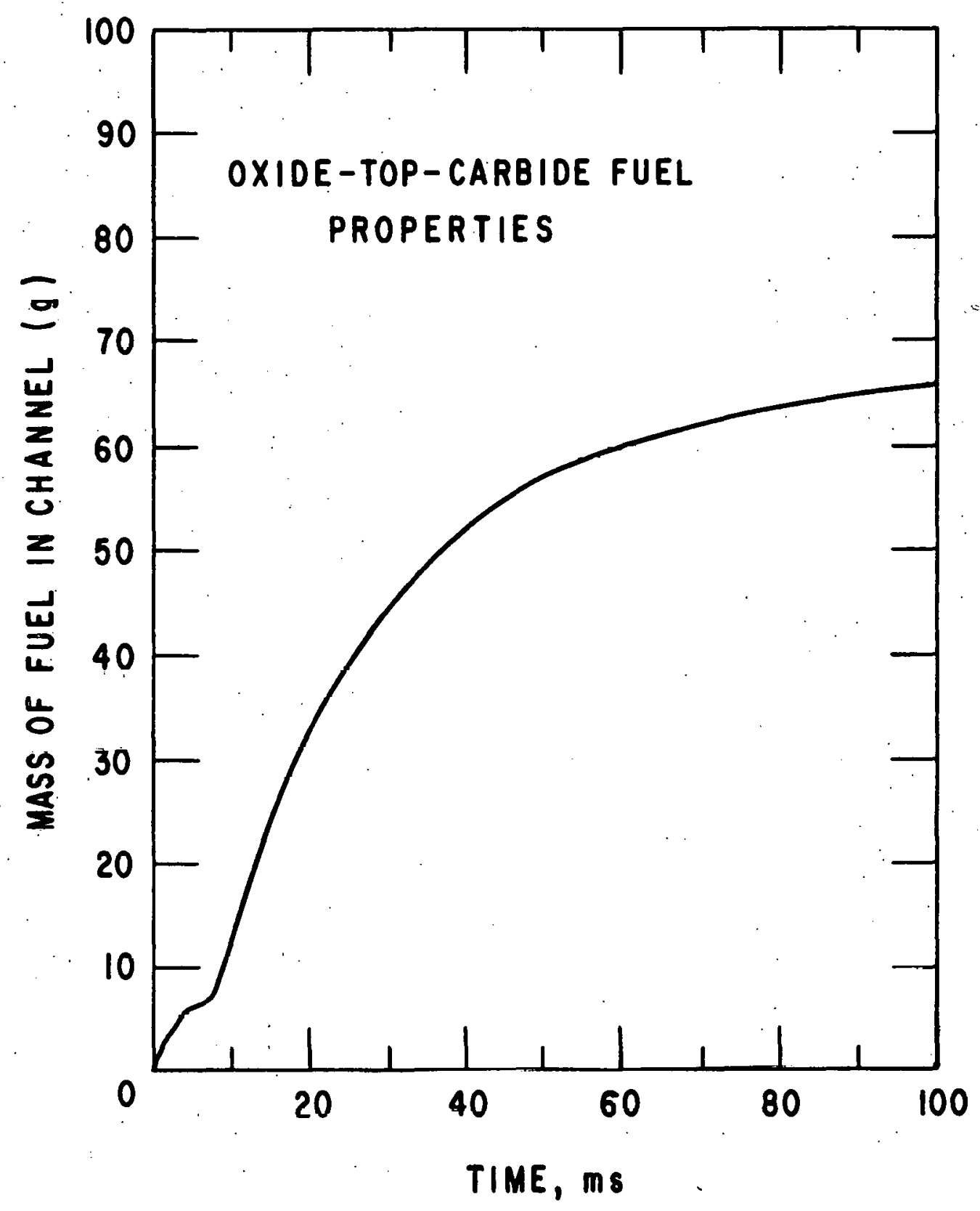

Fig. 16. Mass of Ejected Carbide (Case 4). 